NASA/TM-2014-218137

\title{
Aerodynamic Effects of High Turbulence Intensity on a Variable-Speed Power-Turbine Blade With Large Incidence and Reynolds Number Variations
}

Ashlie B. Flegel

Glenn Research Center, Cleveland, Ohio

Paul W. Giel

Vantage Partners, LLC, Brook Park, Ohio

Gerard E. Welch

Glenn Research Center, Cleveland, Ohio 


\section{NASA STI Program . . . in Profile}

Since its founding, NASA has been dedicated to the advancement of aeronautics and space science. The NASA Scientific and Technical Information (STI) program plays a key part in helping NASA maintain this important role.

The NASA STI Program operates under the auspices of the Agency Chief Information Officer. It collects, organizes, provides for archiving, and disseminates NASA's STI. The NASA STI program provides access to the NASA Aeronautics and Space Database and its public interface, the NASA Technical Reports Server, thus providing one of the largest collections of aeronautical and space science STI in the world. Results are published in both non-NASA channels and by NASA in the NASA STI Report Series, which includes the following report types:

- TECHNICAL PUBLICATION. Reports of completed research or a major significant phase of research that present the results of NASA programs and include extensive data or theoretical analysis. Includes compilations of significant scientific and technical data and information deemed to be of continuing reference value. NASA counterpart of peer-reviewed formal professional papers but has less stringent limitations on manuscript length and extent of graphic presentations.

- TECHNICAL MEMORANDUM. Scientific and technical findings that are preliminary or of specialized interest, e.g., quick release reports, working papers, and bibliographies that contain minimal annotation. Does not contain extensive analysis.

- CONTRACTOR REPORT. Scientific and technical findings by NASA-sponsored contractors and grantees.
- CONFERENCE PUBLICATION. Collected papers from scientific and technical conferences, symposia, seminars, or other meetings sponsored or cosponsored by NASA.

- SPECIAL PUBLICATION. Scientific, technical, or historical information from NASA programs, projects, and missions, often concerned with subjects having substantial public interest.

- TECHNICAL TRANSLATION. Englishlanguage translations of foreign scientific and technical material pertinent to NASA's mission.

Specialized services also include creating custom thesauri, building customized databases, organizing and publishing research results.

For more information about the NASA STI program, see the following:

- Access the NASA STI program home page at http://www.sti.nasa.gov

- E-mail your question to help@sti.nasa.gov

- Fax your question to the NASA STI Information Desk at 443-757-5803

- Phone the NASA STI Information Desk at 443-757-5802

- Write to: STI Information Desk NASA Center for AeroSpace Information 7115 Standard Drive Hanover, MD 21076-1320 
NASA/TM-2014-218137

\section{Aerodynamic Effects of High Turbulence Intensity on a Variable-Speed Power-Turbine Blade With Large Incidence and Reynolds Number Variations}

Ashlie B. Flegel

Glenn Research Center, Cleveland, Ohio

Paul W. Giel

Vantage Partners, LLC, Brook Park, Ohio

Gerard E. Welch

Glenn Research Center, Cleveland, Ohio

Prepared for the

50th Joint Propulsion Conference

cosponsored by AIAA, ASME, SAE, and ASEE

Cleveland, Ohio, July 28-30, 2014

National Aeronautics and

Space Administration

Glenn Research Center

Cleveland, Ohio 44135 


\section{Acknowledgments}

This work was supported under the NASA Fundamental Aeronautics Program, Rotary Wing Project. The authors would like to acknowledge Doug Thurman (Army Research Laboratory) for his assistance with hotwire measurements. The authors also thank Adam Ford, Matt Bloxham, Steve Gegg (deceased), and Ed Turner of Rolls-Royce North American Technologies for their contributions during the blade design efforts under the NASA RTAPS contract. It was the authors' great honor to have worked with Dr. Steven G. Gegg.

This work was sponsored by the Fundamental Aeronautics Program at the NASA Glenn Research Center.

Level of Review: This material has been technically reviewed by technical management.

Available from

NASA Center for Aerospace Information 7115 Standard Drive

Hanover, MD 21076-1320
National Technical Information Service 5301 Shawnee Road Alexandria, VA 22312 


\title{
Aerodynamic Effects of High Turbulence Intensity on a Variable-Speed Power-Turbine Blade With Large Incidence and Reynolds Number Variations
}

\author{
Ashlie B. Flegel \\ National Aeronautics and Space Administration \\ Glenn Research Center \\ Cleveland, Ohio 44135 \\ Paul W. Giel \\ Vantage Partners, LLC \\ Brook Park, Ohio 44142 \\ Gerard E. Welch \\ National Aeronautics and Space Administration \\ Glenn Research Center \\ Cleveland, Ohio 44135
}

\begin{abstract}
The effects of high inlet turbulence intensity on the aerodynamic performance of a variable speed power turbine blade are examined over large incidence and Reynolds number ranges. These results are compared to previous measurements made in a low turbulence environment. Both high and low turbulence studies were conducted in the NASA Glenn Research Center Transonic Turbine Blade Cascade Facility. The purpose of the low inlet turbulence study was to examine the transitional flow effects that are anticipated at cruise Reynolds numbers. The current study extends this to LPT-relevant turbulence levels while perhaps sacrificing transitional flow effects. Assessing the effects of turbulence at these large incidence and Reynolds number variations complements the existing database. Downstream total pressure and exit angle data were acquired for 10 incidence angles ranging from $+15.8^{\circ}$ to $-51.0^{\circ}$. For each incidence angle, data were obtained at five flow conditions with the exit Reynolds number ranging from $2.12 \times 10^{5}$ to $2.12 \times 10^{6}$ and at a design exit Mach number of 0.72 . In order to achieve the lowest Reynolds number, the exit Mach number was reduced to 0.35 due to facility constraints. The inlet turbulence intensity, $T u$, was measured using a single-wire hotwire located 0.415 axial-chord upstream of the blade row. The inlet turbulence levels ranged from 8 to 15 percent for the current study. $T u$ measurements were also made farther upstream so that turbulence decay rates could be calculated as needed for computational inlet boundary conditions. Downstream flow field measurements were obtained using a pneumatic five-hole pitch/yaw probe located in a survey plane 7 percent axial chord aft of the blade trailing edge and covering three blade passages. Blade and endwall static pressures were acquired for each flow condition as well. The blade loading data show that the suction surface separation that was evident at many of the low $T u$ conditions has been eliminated. At the extreme positive and negative incidence angles, the data show substantial differences in the exit flow field. These differences are attributable to both the higher inlet $T u$ directly and to the thinner inlet endwall boundary layer that the turbulence grid imposes.
\end{abstract}

\section{Nomenclature}

$\begin{array}{ll}C p_{s} & \text { static pressure coefficient, } C p_{s}=\left(P-\bar{P}_{2}\right) /\left(P_{t, 1}-\bar{P}_{2}\right) \\ C p_{t} & \text { total pressure coefficient, } C_{p t}=\left(P_{t, 1}-P_{t}\right) / P_{t, 1}-\bar{P}_{2} \\ C_{x} & \text { blade axial chord [in.] }\end{array}$




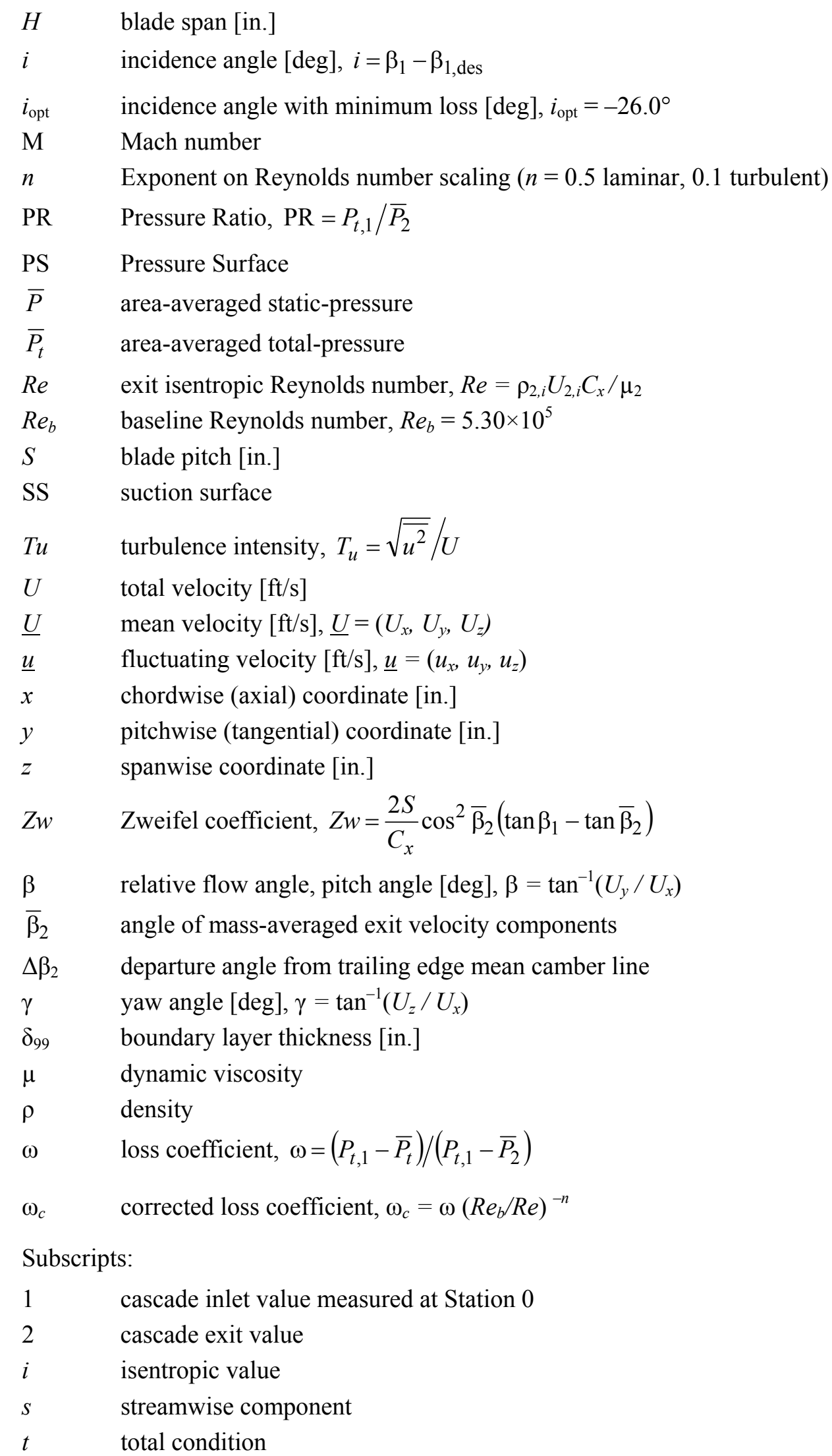




\section{Introduction}

Variable Speed Power Turbine (VSPT) technology has been an area of focus at NASA Glenn Research Center under the Fundamental Aeronautics Program Rotary Wing Project (Ref. 1). The VSPT will have the ability to operate over a large (e.g., 50 percent) shaft-speed range, which enables required main-rotor speed variation of the notional Large Civil Tiltrotor (LCTR) concept. The LCTR could help relieve airport congestion and increase airspace through-put capacity by utilizing its VTOL and Mach 0.5 cruise capability (Refs. 2 and 3). In order to optimize the propulsive efficiency, the main rotors of the LCTR must vary from 100 percent speed at takeoff to 54 percent speed at cruise. The key aerodynamic challenges of the VSPT, due to this speed change, include achieving high turbine efficiency at high work factors, managing the loss levels over a large $\left(40^{\circ}\right.$ to $\left.60^{\circ}\right)$ incidence variation, and operating at low cruise Reynolds numbers at which transitional flow will become a factor. Little data exist in the open literature that examines the effects of a large incidence or Reynolds number variation.

A recent study was conducted on a VSPT blade geometry in NASA's Transonic Turbine Blade Cascade Facility over a $66.8^{\circ}$ incidence range covering an order of magnitude variation of Reynolds numbers ranging from $2.12 \times 10^{5}$ to $2.12 \times 10^{6}$ (Ref. 4). That test was conducted at low inlet turbulence $(T u=0.24$ to 0.4 percent $)$ in order to admit transitional flow on the blade surface since facility limitations did not allow the Reynolds number to be reduced directly to LCTR applicable values. The results of that study showed a significant effect of strong secondary flows associated with high aerodynamic loading levels at the large positive incidence angles. The secondary flows weakened with decreasing aerodynamic

loading at negative incidence conditions and the flow became substantially more two-dimensional. At this low inlet $T u$, the measured blade loadings reflected transitional flow on the suction surface. Inverted (negative) portions of the pressure loading distributions reflected negative flow turning at the higher negative incidence angles. Separation was also noted on the pressure surface at extreme negative incidence angles (Ref. 4).

The focus of this current study is to document the aerodynamic effects of a large range of incidence and Reynolds number variation at engine realistic turbulence levels. An upstream blowing turbulence grid was installed. In addition to producing turbulence, the grid configuration reset and significantly (50 percent) reduced the endwall boundary layer thickness entering the blade cascade. The reduction in inlet boundary-layer thickness had an influence on the aerodynamic blockage levels and total-pressure distribution in the cascade.

The comprehensive database and associated VSPT blade-section geometry is to be made publicly available. The wide incidence range and turbulence intensity range of the test matrix make the dataset of much value for LPT-relevant computational model assessment (e.g., see the recent study by Ameri et al. (Refs. 5 and 6)).

\section{Test Facility, Turbulence Grid, and Blade Description}

\section{Facility}

This study of a two-dimensional VSPT blade section was conducted in the NASA Glenn Research Center (GRC) Transonic Turbine Blade Cascade Facility shown in Figure 1. This facility has been used in several turbine aerodynamic and heat transfer studies, (Refs. 7 to 10) including the assessment of the VSPT blade at low inlet $T u$. The operating envelope shown in Figure 2 demonstrates the large independent range of engine relevant Reynolds and Mach numbers within facility capability. Inlet air is supplied by GRC's 40 psig Combustion Air system. This clean, dry, ambient temperature air enters the facility at a maximum inlet pressure of 14.7 psia under current safety restrictions. This restriction is represented as a red dashed line in Figure 2. The air passes through a series of flow conditioning and contraction sections and is directed into the cascade test section. The air is then discharged into an exhaust header at 2 psia. Valves between the test section and the exhaust header are independently adjusted to give the desired Reynolds and Mach numbers. 


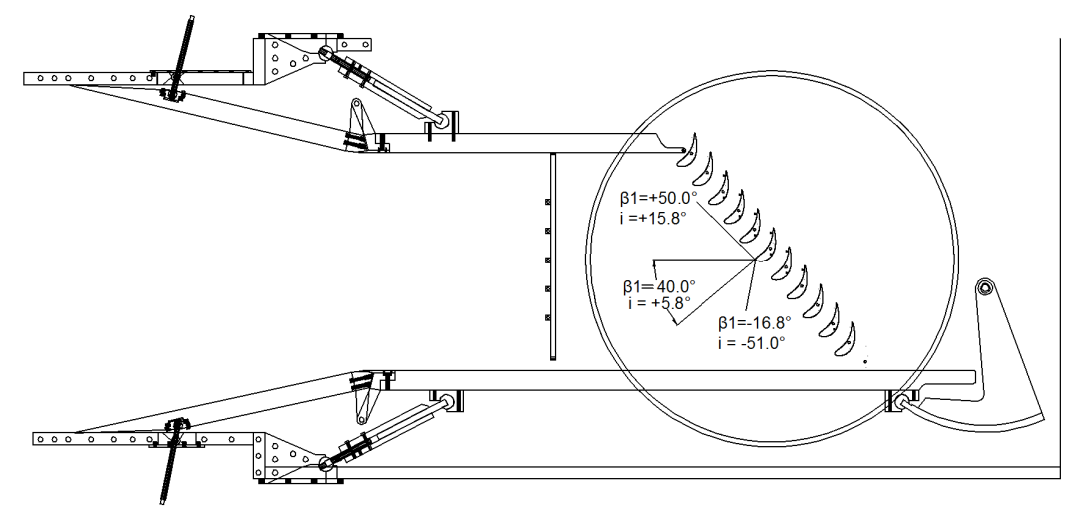

Figure 1.-Cascade layout with VSPT geometry at $i=5.8^{\circ}$.

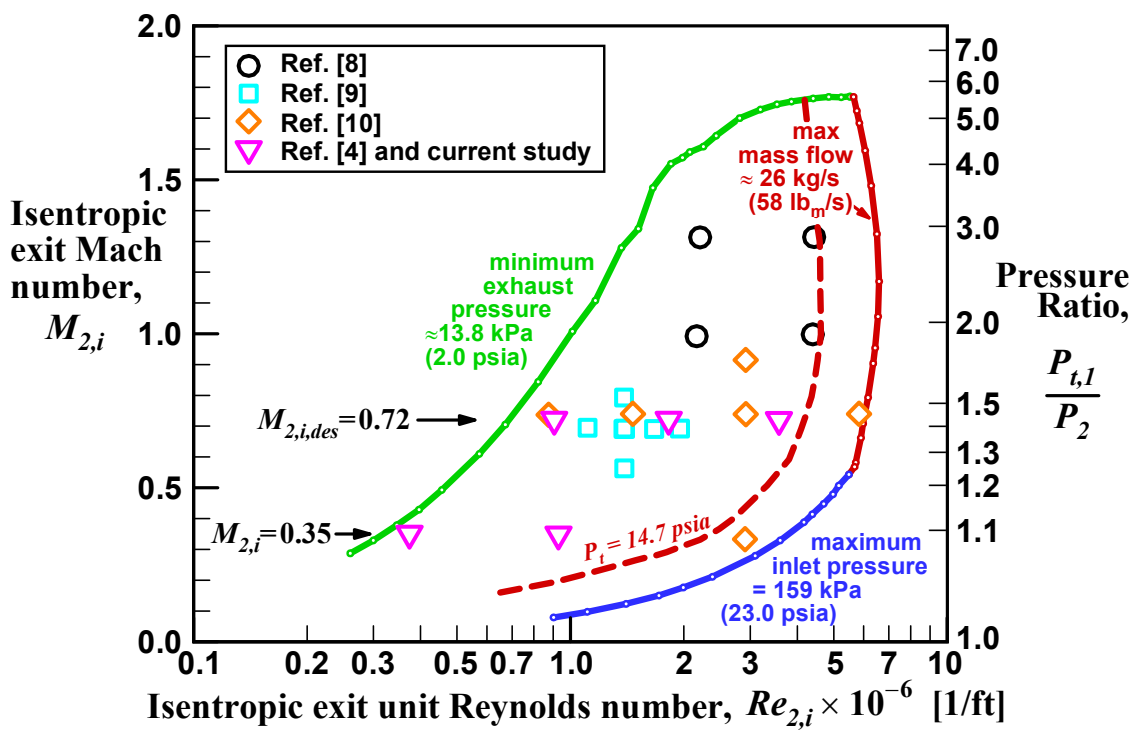

Figure 2.-CW-22 operating envelope.

The cascade test section, illustrated in Figure 1, is made up of nominally 10 blade passages. The blades are mounted on a rotating disk that can set the inlet flow angles (from axial) in the range of $-17^{\circ} \leq$ $\beta_{1} \leq+78.8^{\circ}$. Measurements were acquired at the 10 incidence angles listed in Table 1. Additional detailed measurements were obtained at two angles representing takeoff $\left(i=+5.8^{\circ}\right)$ and cruise $\left(i=-36.7^{\circ}\right)$ flight mission points. Unique upper flow board extensions with respective blade suction-side profiling were installed, replacing the first blade, for five incidence angles in the range of $-16.1^{\circ} \leq i \leq-51.0^{\circ}$. These extensions ensured that the flow was properly directed into the first blade passage, the upper and lower flow boards were horizontal, and their hinged leading edges were maintained in the same plane normal to the inlet flow.

Midspan total-pressure and exit angle data were acquired for each incidence angle tested at five nominal flow conditions. These conditions are represented as the pink triangles in Figure 2 and are listed in Table 2. The design pressure ratio was 1.412, which corresponds to an isentropic exit Mach number of 0.72. A baseline flow condition was achieved by finding the lowest exit Reynolds number at which the tunnel could consistently maintain the design exit Mach number. This baseline Reynolds number, $R e_{b}$, was found to be $0.53 \times 10^{6}$. The Reynolds number was increased to $1.06 \times 10^{6}$ and $2.12 \times 10^{6}$ to examine the effects of higher Reynolds numbers. To reduce Reynolds number to $2.12 \times 10^{5}$ so as to enable an order-ofmagnitude variation of Reynolds number within facility capability, the exit Mach number had to be reduced to $M_{2, i}=0.35$. At this exit Mach number, data were acquired at $R e_{b}$ and at $2.12 \times 10^{5}$ which allowed the Mach number effects to be isolated at $R e_{b}$. 
TABLE 1.-INLET FLOW ANGLES AND

CORRESPONDING ZWEIFEL COEFFICIENT

\begin{tabular}{|c|c|c|}
\hline Inlet angle, & Incidence angle, & $Z w$ \\
$\beta_{1}$ & $15.8^{\circ}$ & 1.22 \\
\hline $50.0^{\circ}$ & $10.8^{\circ}$ & 1.13 \\
$45.0^{\circ}$ & $5.8^{\circ}$ & 1.06 \\
$40.0^{\circ}$ (cruise) & $0.0^{\circ}$ & 0.99 \\
$34.2^{\circ}$ & $-6.2^{\circ}$ & 0.92 \\
$28.0^{\circ}$ & $-16.1^{\circ}$ & 0.82 \\
$18.1^{\circ}$ & $-26.0^{\circ}$ & 0.74 \\
$8.2^{\circ}$ & $-36.7^{\circ}$ & 0.65 \\
$-2.5^{\circ}$ (takeoff) & $-46.0^{\circ}$ & 0.58 \\
$-11.8^{\circ}$ (mission max- $i$ ) & $-51.0^{\circ}$ & 0.53 \\
$-16.8^{\circ}$ & & \\
\hline
\end{tabular}

TABLE 2.-NOMINAL FLOW CONDITIONS

\begin{tabular}{|c|c|c|c|c|c|c|}
\hline \multicolumn{2}{|c|}{ Flow parameters } & \multicolumn{2}{c|}{ Low $T u_{1}$} & \multicolumn{2}{c|}{ High $T u_{1}$} \\
\hline Exit $R e_{C x}$ & $\begin{array}{c}\text { Pressure } \\
\text { ratio }\end{array}$ & Exit $M_{i s}$ & $\begin{array}{c}\delta_{99,1}{ }^{\text {a }} \\
\text { [in.] }\end{array}$ & $2 \delta_{99,1} / H^{\text {a }}$ & $\begin{array}{c}\delta_{99,1}{ }^{\text {a }} \\
\text { [in.] }\end{array}$ & $2 \delta_{99,1} / H^{\text {a }}$ \\
\hline $2.12 \times 10^{6}\left(4.0 \cdot R e_{b}\right)$ & 1.412 & 0.72 & 1.16 to 1.23 & 0.39 to 0.41 & 0.58 to 0.62 & 0.19 to 0.21 \\
\hline $1.06 \times 10^{6}\left(2.0 \cdot R e_{b}\right)$ & 1.412 & 0.72 & 1.28 to 1.36 & 0.43 to 0.45 & 0.64 to 0.69 & 0.21 to 0.23 \\
\hline $5.30 \times 10^{5}\left(1.0 \cdot R e_{b}\right)$ & 1.412 & 0.72 & 1.42 to 1.50 & 0.47 to 0.50 & 0.71 to 0.76 & 0.24 to 0.25 \\
\hline $5.30 \times 10^{5}\left(1.0 \cdot R e_{b}\right)$ & 1.087 & 0.35 & 1.40 to 1.49 & 0.47 to 0.50 & 0.71 to 0.75 & 0.24 to 0.25 \\
\hline $2.12 \times 10^{5}\left(0.4 \cdot R e_{b}\right)$ & 1.087 & 0.35 & 1.60 to 1.69 & 0.53 to 0.56 & 0.81 to 0.86 & 0.27 to 0.29 \\
\hline
\end{tabular}

${ }^{\mathrm{a}}$ Reynolds-scaling estimated range of endwall boundary-layer thickness at cascade inlet over ten incidence angle settings.

Inlet boundary-layer measurements were made at $-0.415 C_{x}$ for $i=+5.8^{\circ}$ and $i=-36.7^{\circ}$; and over the current range of exit Reynolds numbers. The inlet boundary layer measurements indicated that $\delta_{99,1}$ correlated to the inlet Reynolds number only. A boundary-layer thickness correlation was developed of the form $\delta_{99,1} \propto R e_{C x, 1}{ }^{-1 / 7}$ as appropriate for turbulent flow. The inlet boundary layer thickness ranges listed in Table 2 were calculated from the correlation for all 10 incidence angles over the corresponding inlet Reynolds number ranges. It is also important to note that the boundary layer thicknesses decreased by a factor of two for these high $T u$ tests. Even though the boundary layer is reduced upon grid installation, the endwall boundary layers still cover 20 to 30 percent of the blade span.

\section{Turbulence Grid Description}

The focus of this study was to examine the effects of turbulence intensity over a large range of Reynolds number and incidence. To generate turbulence, an upstream blowing turbulence grid was installed roughly five-axial chords upstream of the center of the blade row leading edge. The grid, seen in Figure 1, was made of 1 in. square tubes. A vertical tube spanned the upper and lower inlet board at midspan. Depending on the incidence angle and the distance between the upper and lower inlet boards, the grid consisted of five or six horizontal 1 in. square tubes located on 6 in. centers. Air entered the grid through both ends of the horizontal tubes and exited upstream through 1/8 in. diameter holes. The holes were spaced uniformly on half inch centers and centered on their respective tube. It has been found that this type of grid with upstream blowing produced a more uniform mean and fluctuating flowfield compared to an unblown grid (Ref. 11). The optimum grid blowing ratio was established by surveying the inlet flow at Station 0 (Fig. 3) while varying blowing flow rate until the best mean flow uniformity was achieved.

A constant temperature single-wire hotwire anemometer probe was used to acquire inlet turbulence intensity data. The hotwire was installed in Station 0, located approximately $0.415 C_{x}$ upstream of the blades as shown in Figure 3. The turbulence intensity was documented to be between 8 to 15 percent, depending on inlet flow angle and the resultant distance between the upstream grid and cascade inlet. Details of the hotwire measurements can be found in Thurman et al. (Ref. 12). 

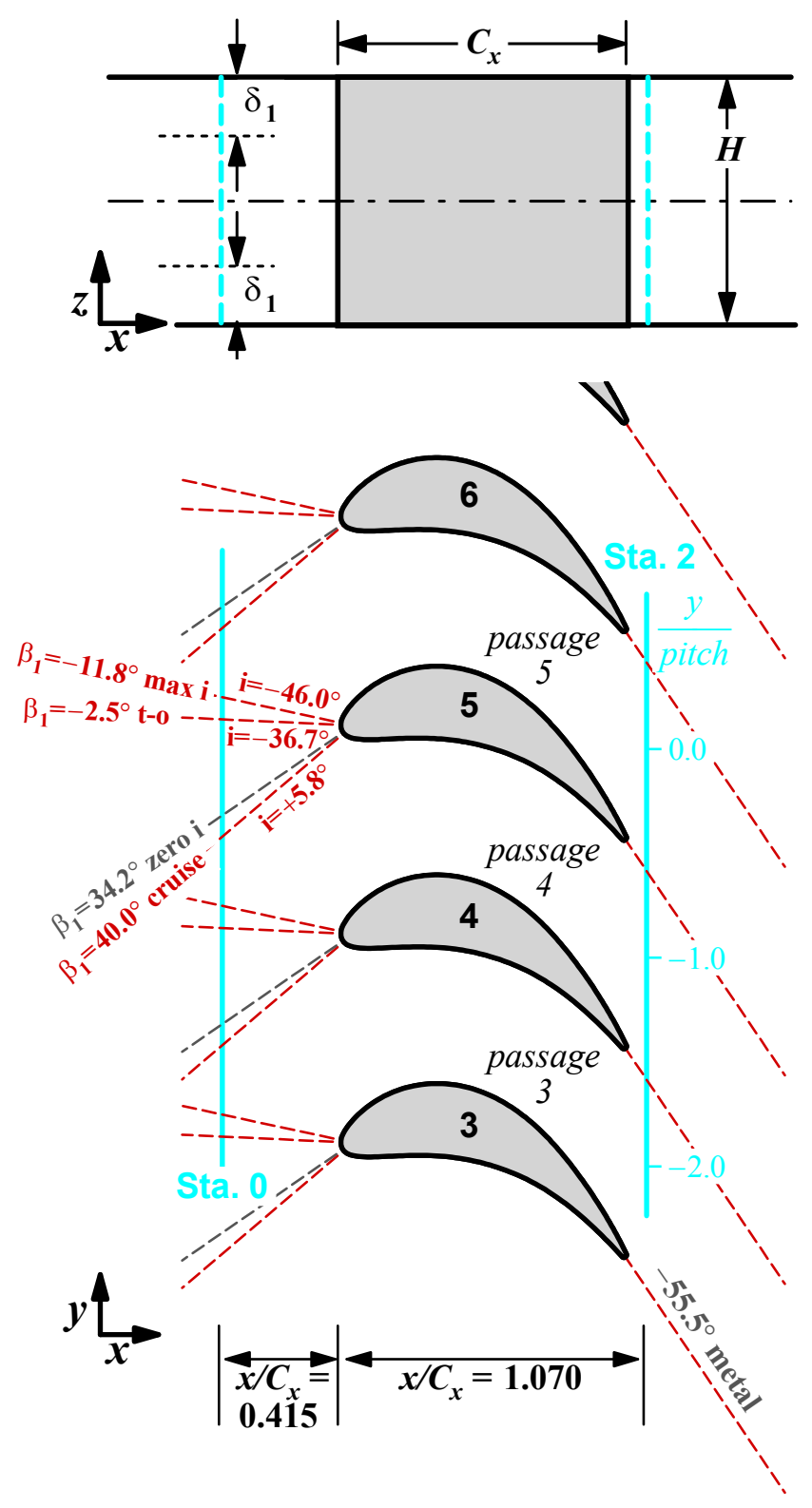

Figure 3._VSPT blade and measurement plane details.

\section{Blade Description}

The blade geometry is a scaled-up two-dimensional midspan section of a second-stage rotor of the 4-stage VSPT design (Ref. 13). Details of the blade and the design/optimization process used to establish the two-dimensional profile are documented elsewhere (Refs. 4 and 13). The blade geometry is shown in Figure 3 and details of the scaled (test) blade are described in Table 3.

A computed design-point blade loading diagram is compared to the experimental data from the previous low $T u$ test and the current high $T u$ test in Figure 4. The experimental data is taken at midspan for two Reynolds number conditions. The design calculation (Ref. 13) was carried out on a twodimensional cone assuming fully turbulent flow. It is noted that the high $T u$ data correspond very well with the design intent throughout the front portion of the blade; however the disparity between computed and measured pressure coefficients on in the aft portion of the blade, on pressure side and suction side, is 
TABLE 3.-BLADE DESCRIPTION

\begin{tabular}{|l|l|}
\hline \multicolumn{1}{|c|}{ Parameter } & \multicolumn{1}{|c|}{ Value } \\
\hline Axial chord, $C_{x}$ & $180.57 \mathrm{~mm}$ (7.109 in.) \\
True chord & $194.44 \mathrm{~mm}$ (7.655 in.) \\
Pitch, $S$ & $130.00 \mathrm{~mm}$ (5.119 in.) \\
Span, $H$ & $152.40 \mathrm{~mm}$ (6.000 in.) \\
Throat dimension & $72.85 \mathrm{~mm}(2.868$ in.) \\
Leading edge diameter & $15.16 \mathrm{~mm}(0.597$ in.) \\
Trailing edge diameter & $3.30 \mathrm{~mm}(0.130$ in.) \\
Stagger angle & $20.35^{\circ}$ \\
Inlet metal angle & $34.2^{\circ}$ \\
Uncovered turning & $19.47^{\circ}$ \\
Exit metal angle & $-55.54^{\circ}$ \\
\hline
\end{tabular}

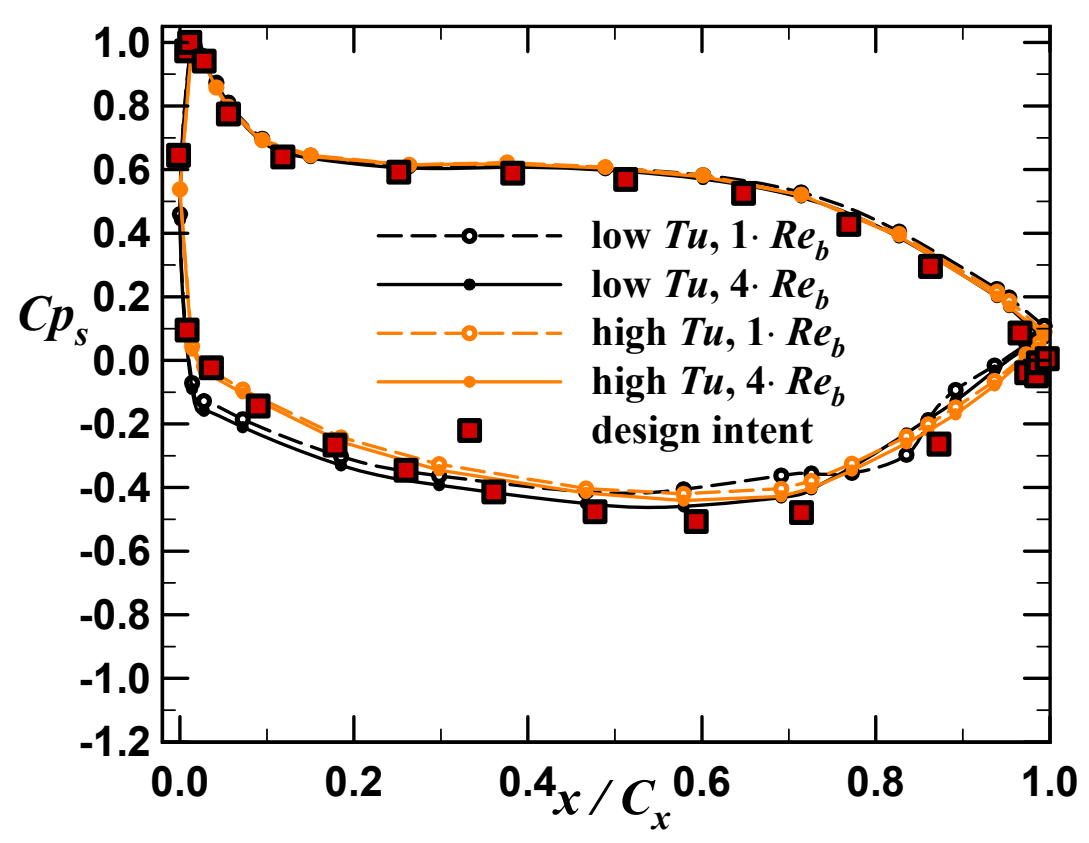

Figure 4.-Design intent and experimental data at $i=+5.8^{\circ}$.

evident. This may be attributed, in part, to differences in the reference exit-pressure of the pressure coefficients in computation and experiment. The disparity might also be associated with streamtube contraction in experiment due to the endwall blockage that is not present in the CFD. The low $T u$ data indicate a region of transition at $x / C_{x}=0.85$ which is influenced by the strong three-dimensionally and secondary flow fields in the low aspect ratio cascade (Fig. 3).

\section{Measurement Description}

Total-pressure and exit flow angle data were obtained using a five-hole pitch-yaw probe installed in the Station 2 survey plane shown in Figure 3. The survey plane is located approximately 7.0 percent axial-chord downstream of the blade trailing edge and covers three blade passages. The five-hole probe is a $45^{\circ}$ forward-facing pyramid probe with the measurement port located on the shaft centerline. Midspan surveys were obtained for all 10 incidence angles consisting of 123 pitchwise points spaced non-uniformly over three blade passages. For incidence angles $+5.8^{\circ}$ (cruise) and $-36.7^{\circ}$ (takeoff), additional surveys were acquired at 12 spanwise immersions uniformly spaced from $0.042 \leq z / H \leq 0.50$. For these surveys, each spanwise point consisted of 62 pitchwise points spaced uniformly across three blade passages. 
Detailed probe descriptions and calibration methods were described in Giel et al. (Ref. 8). The time response of the five-hole probe was measured to be $0.42 \mathrm{~s}$. A $3 \mathrm{sec}$ delay was imposed between the time the probe reached the desired survey location and the data recording initiation to ensure a

95 percent time recovery. During each survey, the probe was monitored to ensure it remained well within the angular calibration range of $\pm 40^{\circ}$. The overall estimated absolute uncertainty in flow angle was $\pm 1.5^{\circ}$ and the overall estimated local uncertainty in total-pressure coefficient was \pm 0.01 based on the analysis reported in Giel et al. (Ref. 8).

The primary measurement blades 4,5 , and 6 were instrumented with static pressure taps at four spanwise locations. Blade 5 was fully instrumented on the pressure and suction surfaces with 44 taps located at 10, 15, 30, and 50 span. Blade 4 was instrumented with 20 redundant taps on the suction side and blade 6 had 16 redundant taps on the pressure side. The endwall was also fully instrumented with static taps located upstream and downstream of the blade row and within the blade passages.

The exit Mach number condition was set by the average of 12 exit static-pressure taps located approximately three axial-chords downstream of the blades and spanning nine blade pitches. The inlet static pressure was measured by five to six inlet static pressure taps located $2.95 \mathrm{in}$. upstream of the blade row at Station 0. Inlet total pressure and temperature were measured with two combination Kiel/totaltemperature probes located upstream at midspan in Station 0, just outside the passages measured by the downstream survey probe.

\section{Results}

\section{Impact of the Turbulence Grid and Incidence on the Three-Dimensional Flowfield}

Survey Data-Detailed flowfield surveys were acquired for the cruise $\left(i=+5.8^{\circ}, \beta_{2}=40.0^{\circ}\right)$ and takeoff $\left(i=-36.7^{\circ}, \beta_{2}=-2.5^{\circ}\right)$ incidence angles at the baseline Reynolds number $\left(R e_{b}\right)$ and nominal design exit Mach number $\left(M_{2}=0.72\right)$. The current high $T u$ data were acquired with a five-hole probe over 12 pitchwise surveys at spanwise immersions between $0.042<z / H \leq 0.50$. For the previous low inlet $T u$ data, 14 additional spanwise points were acquired with a three-hole probe in the near-wall region between $0.0<z / H \leq 0.043$. Total pressure coefficient contours for the positive incidence, $i=+5.8^{\circ}$, are shown in Figure 5. At low inlet $T u$ (Fig. 5(a)), the blade is highly loaded producing strong secondary flows that transport the thick (e.g., 50 percent of the half-span) endwall flow to and along the suction side of the blade. A region of elevated $C p_{t}$ in the wake at midspan reflects separation, transition, and reattachment at low $T u$ (also evident in Fig. 4). At the same highly loaded condition, but with the blown turbulence grid installed (high $T u$ ), the impact of reduced inlet boundary layer thickness is evident in Figure 5(b) in that far less low total pressure flow has accumulated on the blade suction-side; furthermore, the midspan wake loss levels are lower, reflecting that the flow in the high $T u$ environment remains attached (no suctionside separation, see Fig. 4).

At the high negative incidence condition (Fig. 6), the blade loading is reduced and the flow becomes largely two-dimensional. As the strength of the secondary flow is reduced at the low load condition, transport of the boundary layer flow up the suction-side is reduced. The thick boundary layer of the low $T u$ (Fig. 6(a)) remains near the endwall.

All of the total-pressure contours for both inlet angles show good passage-to-passage periodicity. Note that the periodicity improved for the high $T u$ case.

Figure 7 shows secondary flow vectors overlaid on the total-pressure contours (Fig. 7(a)), pitch angle contours (Fig. 7(b)), and yaw angle contours (Fig. 7(c)) at high inlet $T u$ for the positive incidence $\left(i=+5.8^{\circ}\right)$ condition over a single passage. Near the endwall $(z / H=0.04)$ there is evidence of strong overturning at the hub. The reduced inlet boundary layer of the high $T u$ configuration causes the secondary flow vectors to diminish as compared to the low $T u$ data shown in Figure 8(a), with less evidence of the horseshoe and passage vortices. Since the flow is more two-dimensional for $i=-36.7^{\circ}$, there is little variation as shown in Figure 9. 


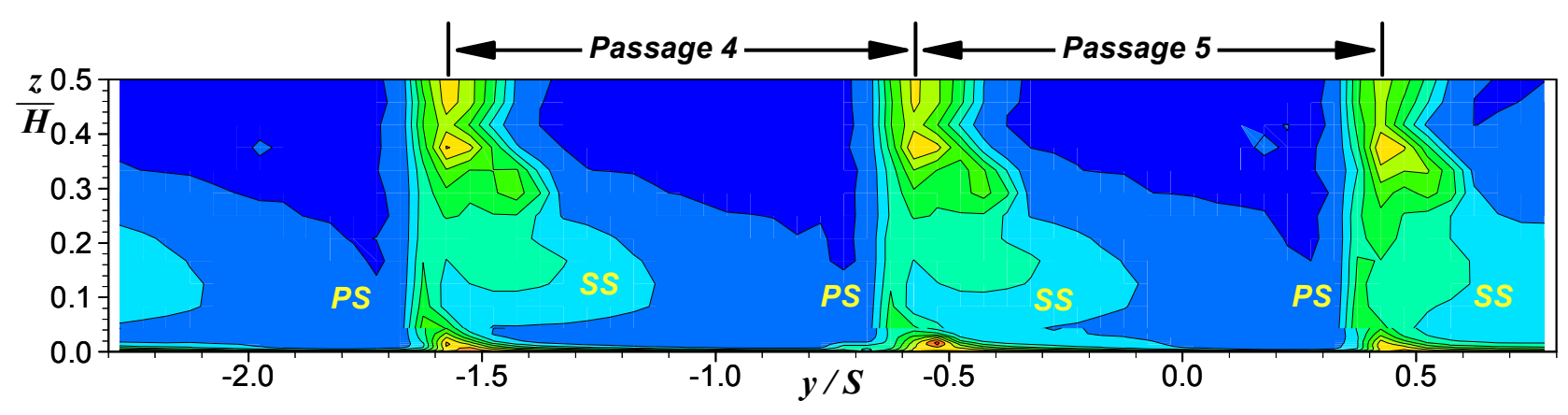

(a) Low $T u$

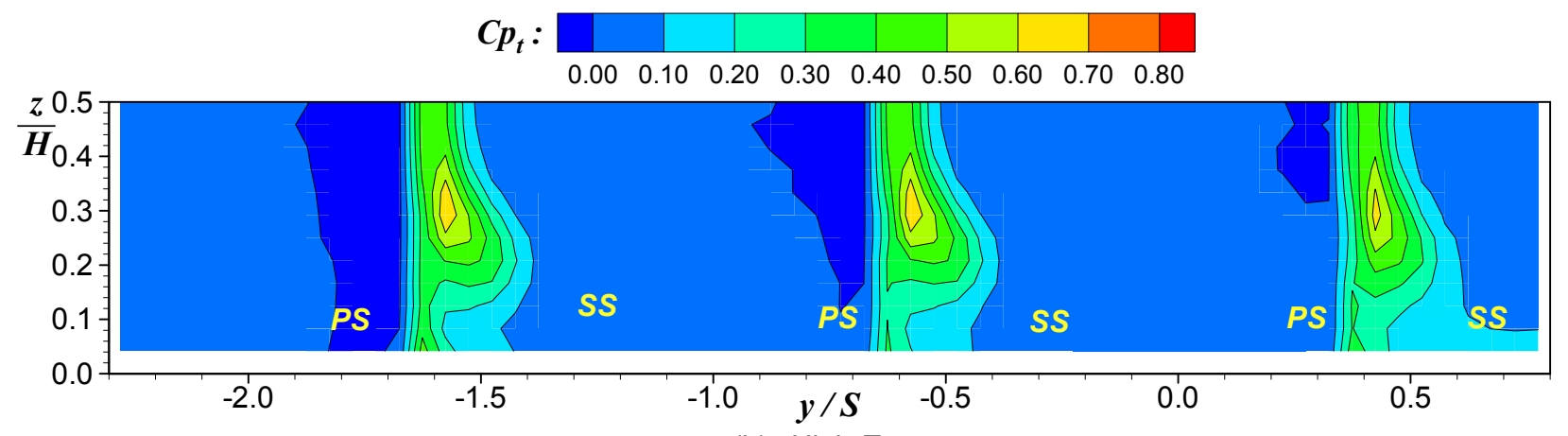

(b) High $T u$

Figure 5.-Total pressure coefficient contours at $R e_{b}$ and $M_{2, i}=0.72$ at $i=+5.8^{\circ}$.

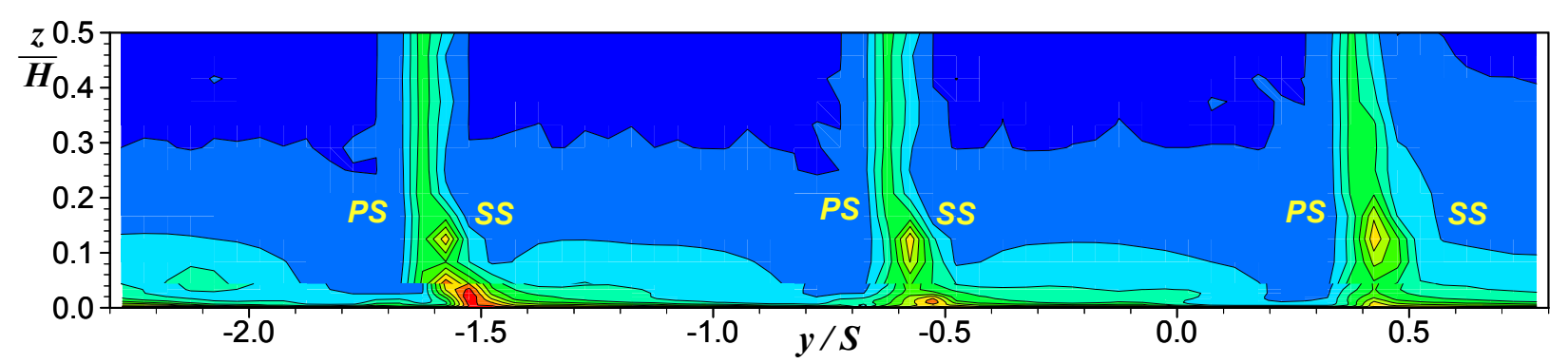

(a) Low $T u$

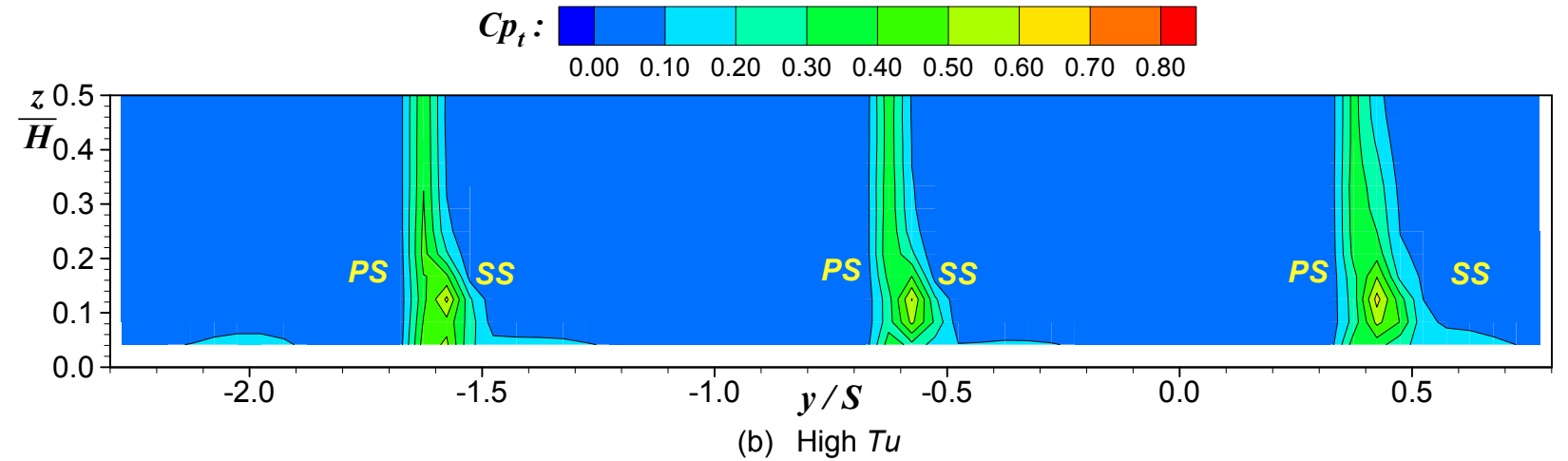

Figure 6. -Total pressure coefficient contours at $R e_{b}$ and $M_{2, i}=0.72$ at $i=-36.7^{\circ}$. 


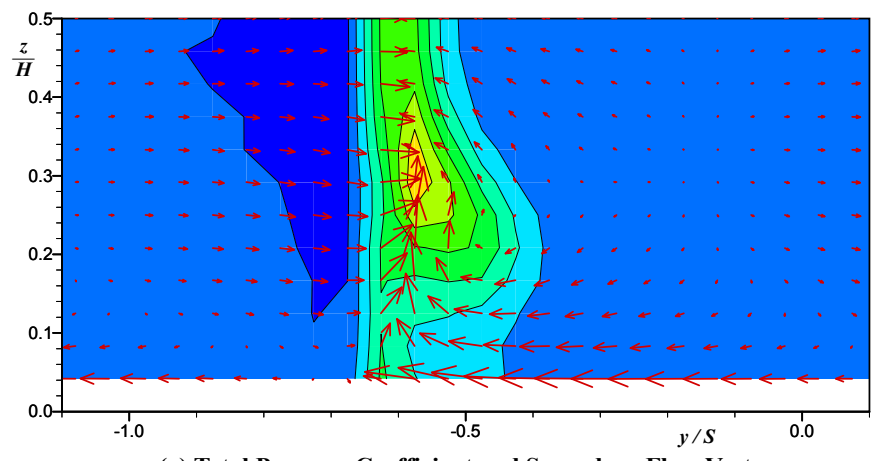

(a) Total Pressure Coefficient and Secondary Flow Vectors

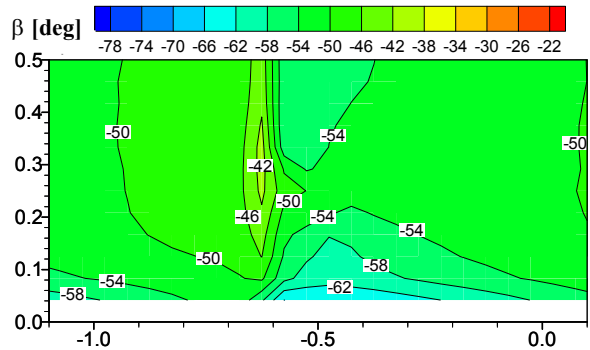

(b) Pitch Angle, $\beta[\mathrm{deg}]$

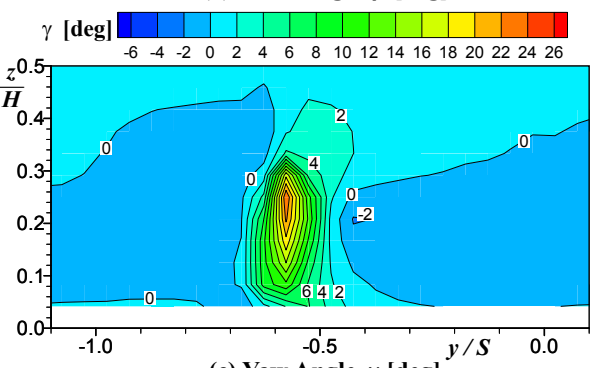

(c) Yaw Angle, $v$ [deg]

Figure 7.—Detailed view of high $T u$ flow at $i=+5.8^{\circ}, R_{b}, M_{2, i}=0.72$.

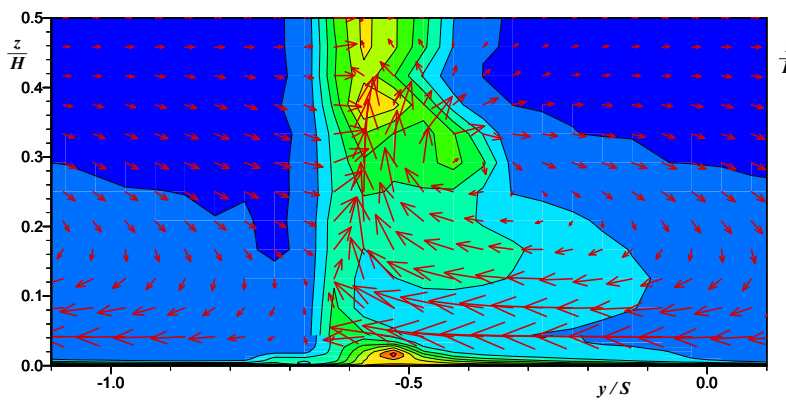

(a)

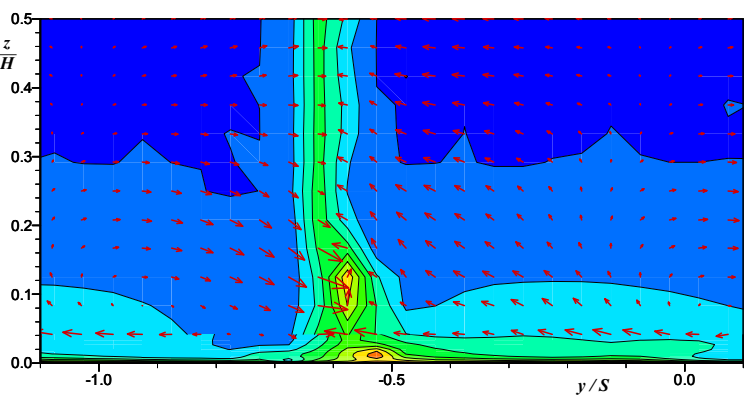

(b)

Figure 8.-Low Tu secondary flow contours at (a) $i=+5.8^{\circ}$ and (b) at $i=-36.7^{\circ} ; \operatorname{Re}_{b}, M_{2, i}=0.72$.

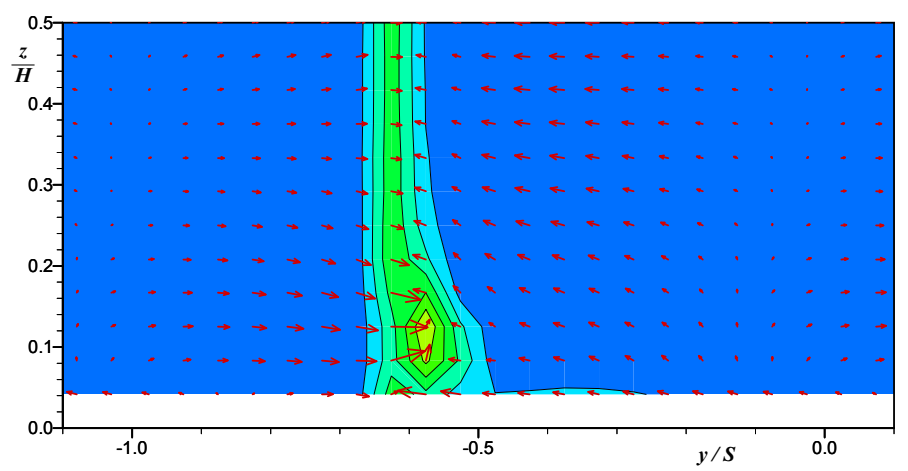

(a) Total Pressure Coefficient and Secondary Flow Vectors

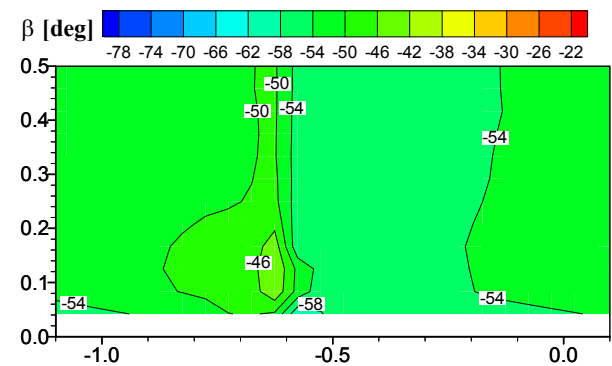

(b) Pitch Angle, $\beta$ [deg]

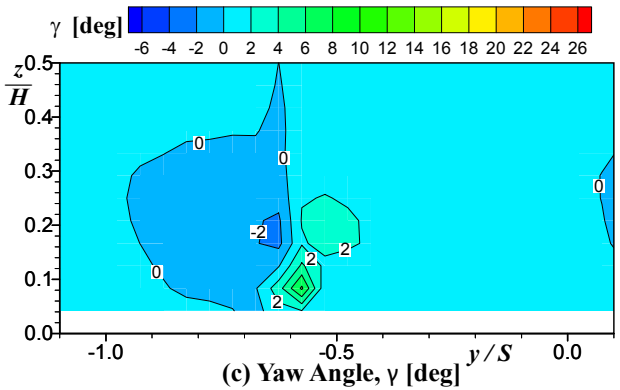

Figure 9.—Detailed view contours of high $T u$ flow at $i=-36.7^{\circ}, R e_{b}, M_{2, i}=0.72$. 


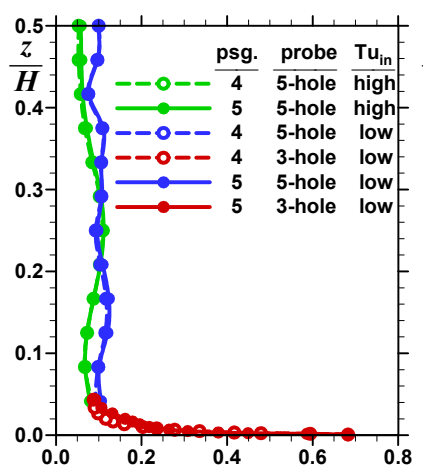

(a) $C p_{t}$ (Area Averaged)

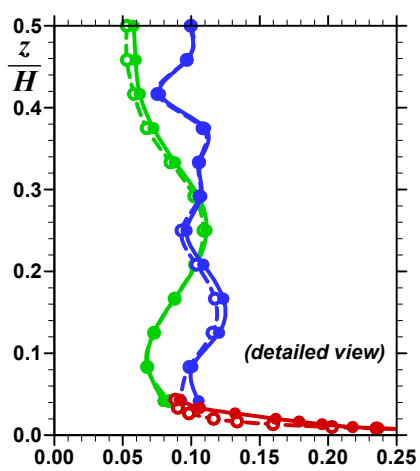

(b) $C p_{t}$ (Area Averaged)

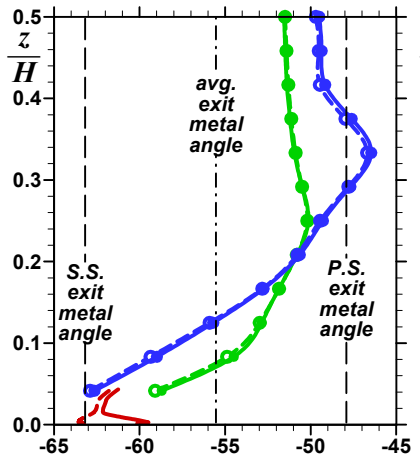

(c) $\beta[\mathrm{deg}]$ (Mass Averaged)

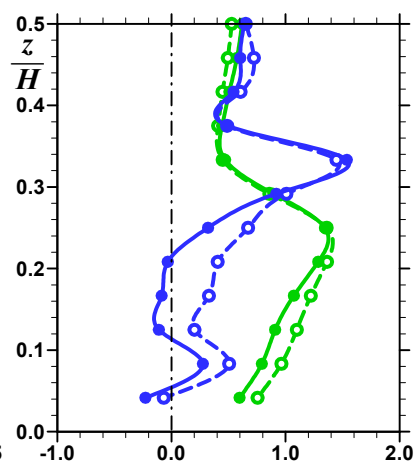

(d) $\gamma[\mathrm{deg}]$ (Mass Averaged)

Figure 10.-Pitchwise integrations for $i=+5.8^{\circ}$.

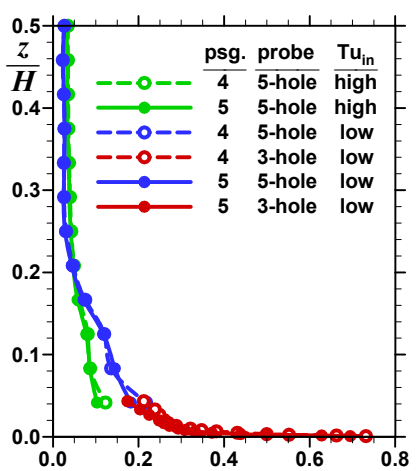

(a) $C p_{t}$ (Area Averaged)

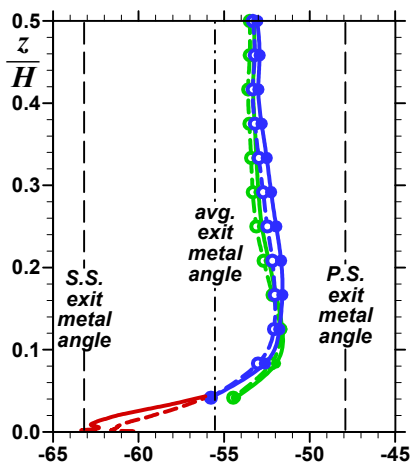

(c) $\beta[\mathbf{d e g}]$ (Mass Averaged)

Figure 11.-Pitchwise integrations for $i=-36.7^{\circ}$

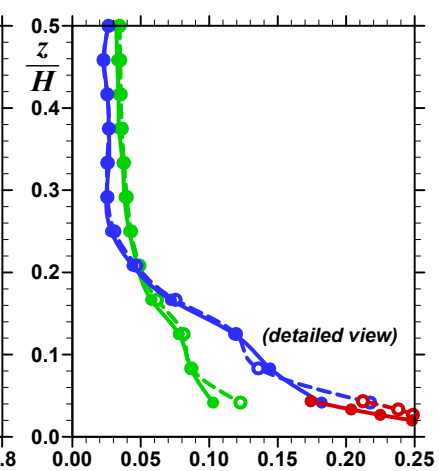

(b) $C p_{t}$ (Area Averaged)

Pitchwise Integrations - Pitchwise integrations of the total-pressure, pitch angle, and yaw angle were calculated at each spanwise immersion for $i=+5.8^{\circ}$ (Fig. 10) and $i=-36.7^{\circ}$ (Fig. 11). For each angle, the high $T u$ results are compared to the low $T u$ results. The area-averaged total-pressure coefficients for the high $T u$ data (Fig. 10(a) and (b), green lines) show a reduction in total-pressure variation along most of the blade span. In Figure 10(c) and (d), the maxima at $z / H=0.33$ of the low $T u$ results reflects the core of the horseshoe vortex (Fig. 8(a)). With a thinner endwall boundary layer in the grid configuration (high $\mathrm{Tu}$ ), the core of the horseshoe vortex, which rises over the transported endwall flow, adopts a lower spanwise position of $z / H=0.24$ (also see Fig. 7(a)).

Pitchwise integrations for $i=-36.7^{\circ}$ are shown in Figure 11. The total-pressure coefficients (Fig. 11(a) and (b)) at this incidence angle reflect the boundary layer that remains intact as it passes through the blade. As seen in Table 1, the boundary layer is reduced in size by half for the high $T u$ data. Figure 11(b) shows the differences in boundary layer thickness. The total pressure coefficient at midspan for the high $T u$ configuration is comparable to that of the low $T u$, which will be shown to exhibit a suction-side laminar separation/transition/reattachment. Consistent with the contours shown in Figures 6 and 8, the pitch and yaw angles (Fig. 11(c) and (d)) do not show any variation due to an increase in $T u$.

\section{Effect of Turbulence on the Blade Loading}

While the exit flowfield is strongly influenced by the inlet boundary layer thickness, the midspan loading diagrams more directly reflect the impact of turbulence level on transition and separation/ reattachment. The effects of incidence and Reynolds number on the blade loading are show in Figure 12 for low $T u$ and Figure 13 for high $T u$. All data were acquired at the nominal design exit Mach number except as noted, due to facility limitations. Each figure is arranged with the highest Reynolds number $\left(4 \cdot R e_{b}\right)$ on the left and the baseline Reynolds number $\left(R e_{b}\right)$ on the right. The angles presented cover the entire tested incidence range. 

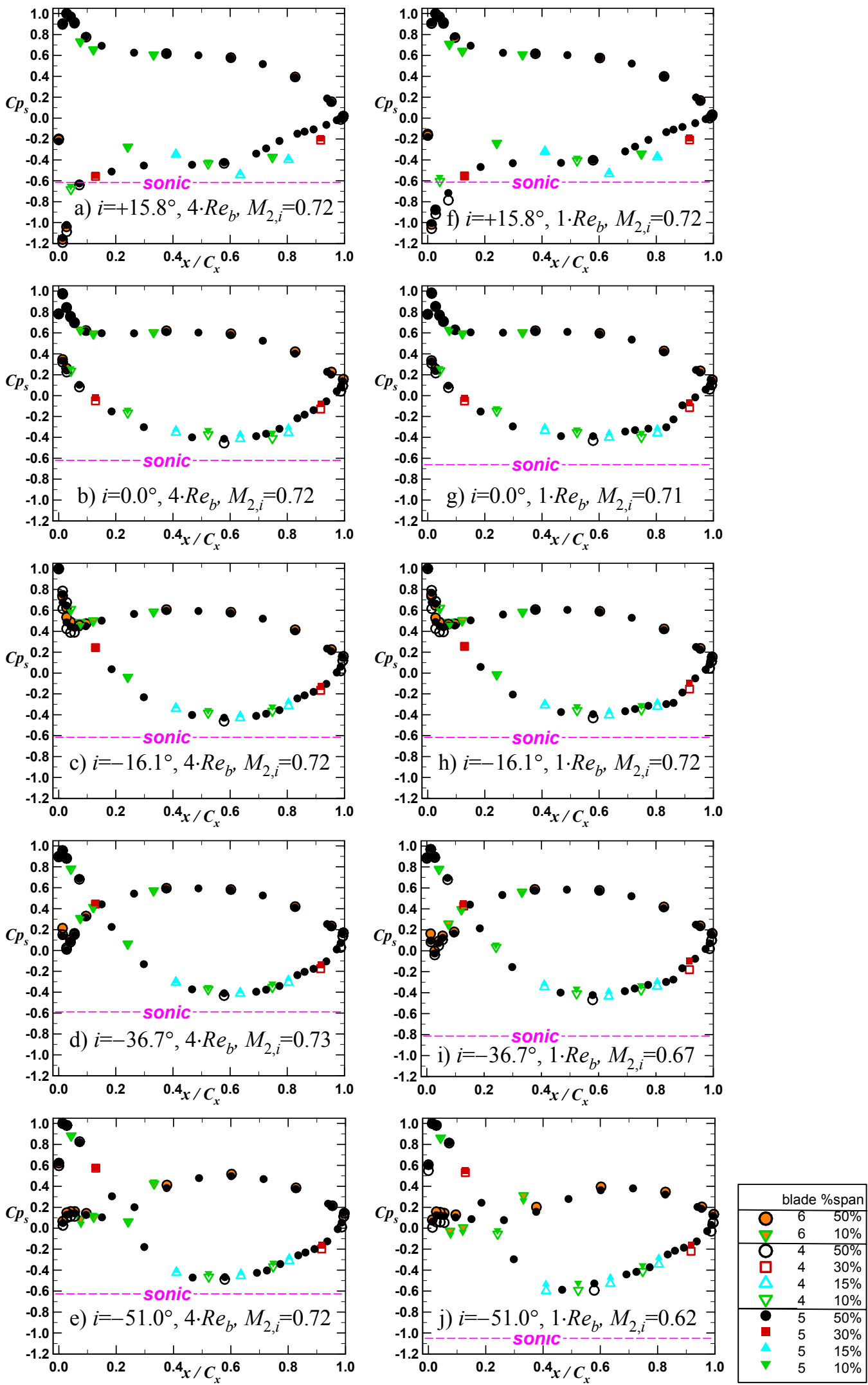

Figure 12.-Blade loading (low $T u$ ) - effects of incidence and Reynolds at number at nominal design exit Mach number. 

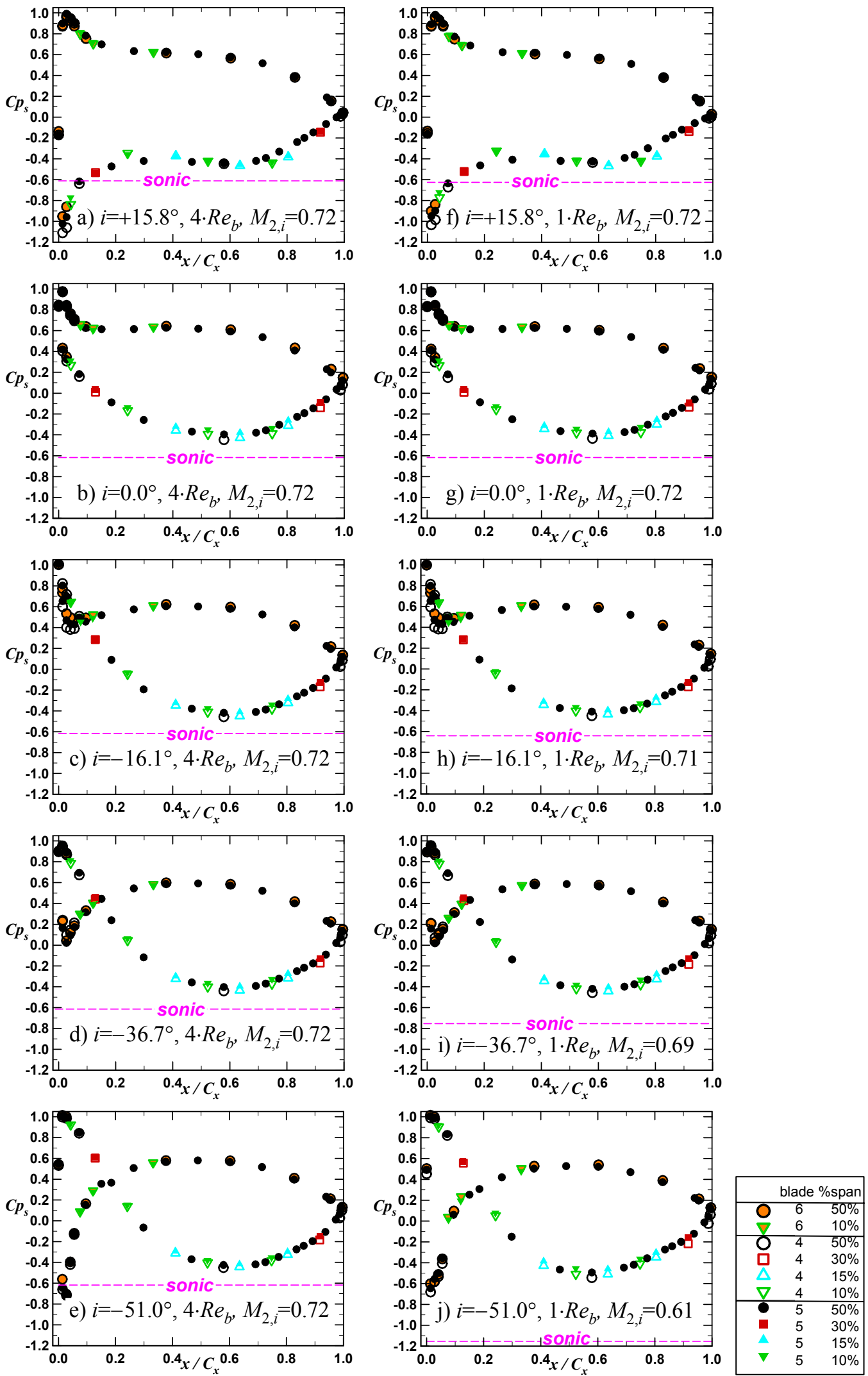

Figure 13.-Blade loading (high $T u$ )—effects of incidence and Reynolds at number at nominal design exit Mach number. 
At the highest positive incidence and the baseline Reynolds number $\left(R e_{b}\right)$ condition, the low $T u$ flow exhibits suction-surface separation and reattachment at $x / C_{x}=0.85$. This is demonstrated as a neutral pressure gradient region, followed by an abrupt diffusion (Ref. 14). The high Tu blade loading in Figure 13(a) and (f) show that the flow is attached over the entire blade surface - results are comparable to the low $T u$ case at the higher $4 \cdot R e_{b}$ flow condition. For both $T u$ cases, the positive incidence results in high blade loading. The three-dimensionality of the flow can be seen in the spanwise loading variations in Figure 12(a) and (f). The magnitude of variations is reduced at high $T u$ and periodicity is improved. Note that for both $T u$ levels, small supersonic overspeed flow regions exist on the suction surface near the leading edge.

As seen in the total pressure coefficient contours of Figure 6, as the incidence decreases the blade unloads and the flow becomes more two-dimensional. For both $T u$ cases, negative loading is measured on the front portion of the blade for $i<-16.1^{\circ}$. At $i=-36.7^{\circ}$ pressure-side cove separation is observed at low $T u$ but the flow remains attached at high $T u$. In fact, at high $T u$, neither suction-side nor pressure-side separation were observed for any operating point within the full range of text-matrix incidence and Reynolds number. The effects of a thinner boundary layer and increased $T u$ reflect that the flow over the blade becomes two-dimensional very quickly with decreasing incidence. The only time the blade indicates signs of secondary flows (spanwise variation) is at the most positive incidence angle.

The effects of exit Mach number variation at fixed Reynolds number on blade loading was investigated. The results from the low $T u$ study showed that as the exit Mach number is reduced from the nominal $M_{2, i}=0.72$ to $M_{2, i}=0.35$, the loading increases and the location of minimum $C p_{s}$ moves forward (Ref. 4). The same results were found when tested at high inlet $T u$; therefore those results will not be presented here.

\section{Midspan Exit Total-Pressure and Flow Angle Surveys}

Midspan total-pressure and exit flow angle surveys were acquired for each incidence angle. Each survey consisted of 132 points concentrated in the wakes of three passages. The effects of Tu, Reynolds number, and Mach number variations on the wake profile are presented in Figures 14 to 18 . At the high positive incidence angle of $i=+10.8^{\circ}$ (Fig. 14), it is noted that the wake width and depth increases with decreasing Reynolds number and Mach number. At a high positive incidence the blade row is highly loaded and the large suction side thickening is consistent with the separation (low Tu only) and high loading observed in the blade loading diagrams. For the high $T u$ case (Fig. 14(b)), there is minimal thickening of the suction-side boundary-layer/wake as compared to the same in the low inlet $T u$ case (Fig. 14(a)). It is noted that wakes are more periodic for the high $T u$ and thinner inlet boundary layer. Both $T u$ cases show that the exit flow angles are independent of Reynolds number and decrease as the Mach number is reduced.

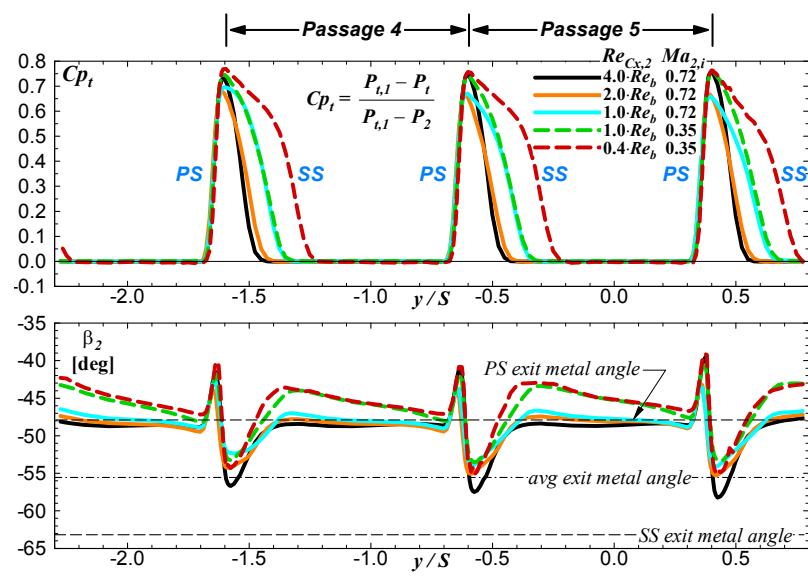

(a) Low $T u$

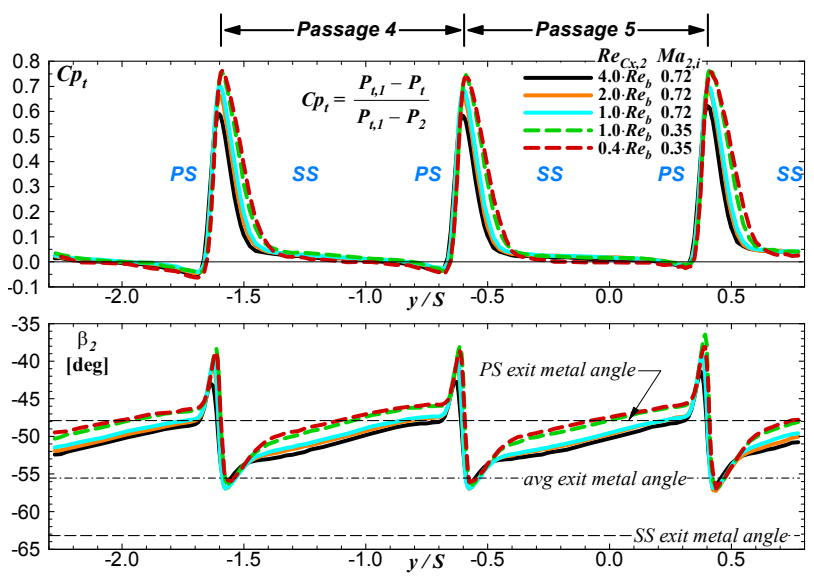

(b) High $T u$

Figure 14.-Effects of Reynolds number and exit Mach number at $i=+10.8^{\circ}$. 


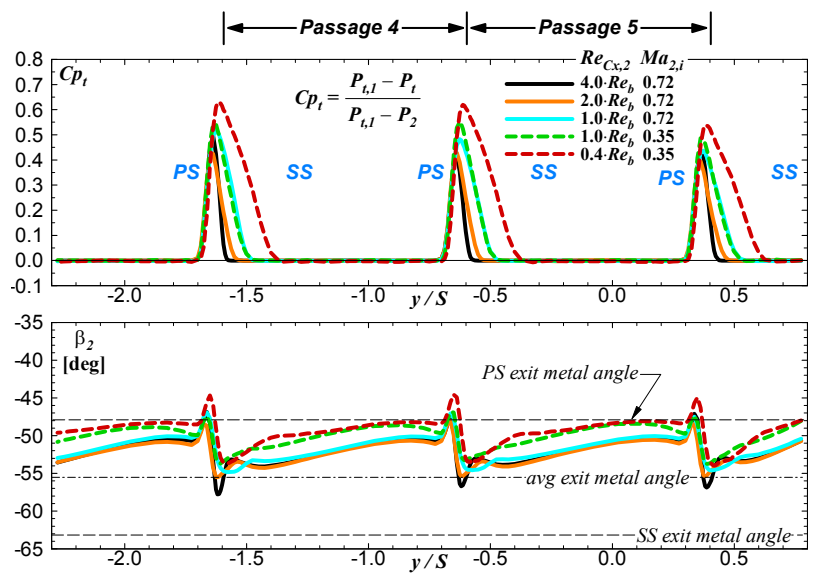

(a) Low $T u$

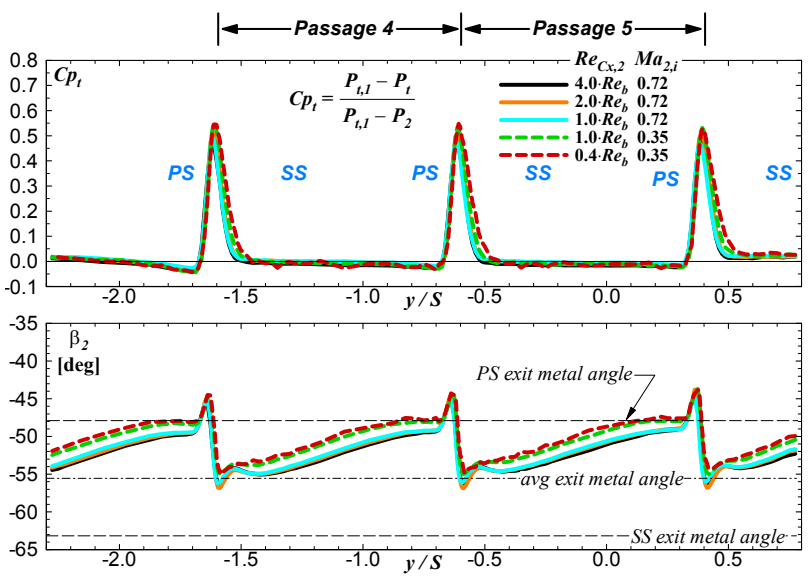

(b) High $T u$

Figure 15.-Effects of Reynolds number and exit Mach number at $i=0.0^{\circ}$.

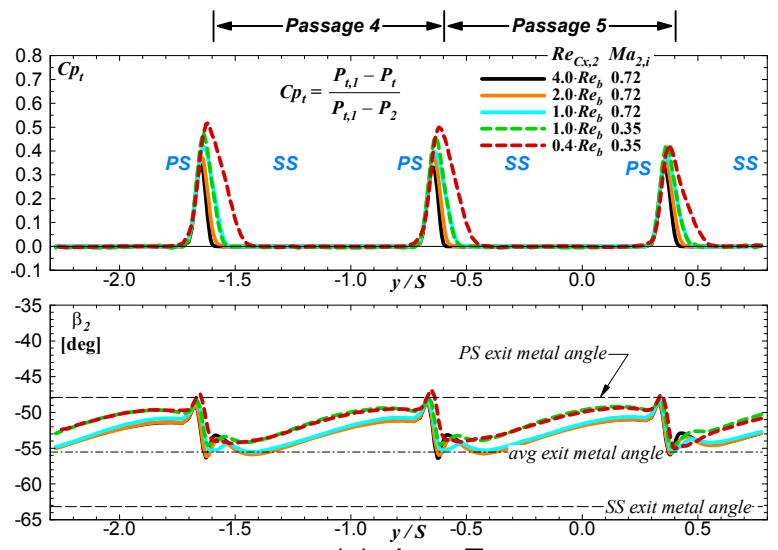

(a) Low Tu

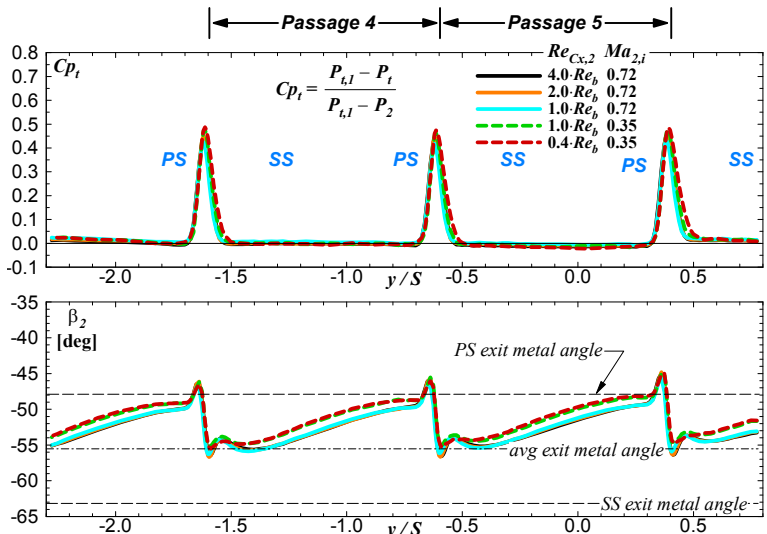

(b) High $\mathrm{Tu}$

Figure 16. - Effects of Reynolds number and exit Mach number at $i=-16.1^{\circ}$.

As the incidence angle decreases, the trends in the total-pressure and exit flow angles remain the same but the low $T u$ exhibits a larger suction side boundary-layer/wake thickening while the high $T u$ total pressure and exit flow angles vary only slightly with decreasing Reynolds number, see Figure 15. As incidence decreases to a negative value (Fig. 16(a)), the high $T u$ wake is very similar to the $i=-36.7^{\circ}$ wake profile at low $T u$ (Fig. 17(a)), which corresponds to the incidence with minimum loss at low $T u$ (Ref. 4).

The highest negative incidence, $i=-51.0^{\circ}$, is shown in Figure 18. At low inlet $T u$, the pressure side separation spans across a majority of the passage (Fig. 18(a)). This massive separation is associated with aerodynamic blockage. The PS wake depth and width increase significantly with decreasing Reynolds number. The suction side wake width also increases slightly with decreasing Reynolds number. The exit flow angles show a significant decrease, near the average exit metal angle, compared to the previous incidence angles. The angles vary little with decreasing Reynolds and Mach number except at the highest Reynolds number condition $\left(4 \cdot R e_{b}\right)$. In the previous study (Ref. 4$)$ it was concluded that at this extreme negative incidence, as the Reynolds number decreases the PS induced wake thickens substantially causing an aerodynamic blockage that resets the aerodynamic throat upstream and effects increased turning resulting in an increased negative discharge angle. At the high inlet $T u$ (Fig. 18(b)), the flow remains largely attached and a gross pressure-side separation is not seen. As the Reynolds number decreases, the wake thickness increases slightly on the pressure side. At the lowest Reynolds number $\left(0.4 \cdot R e_{b}\right)$ the wake does indicate a pressure-side separation. The exit flow angles remain consistent and vary slightly with decreasing Reynolds number. 


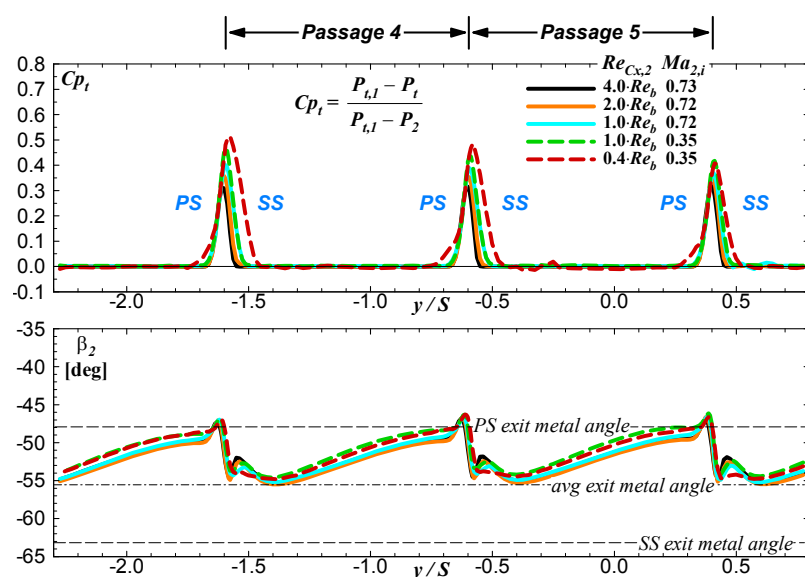

(a) Low $T u$

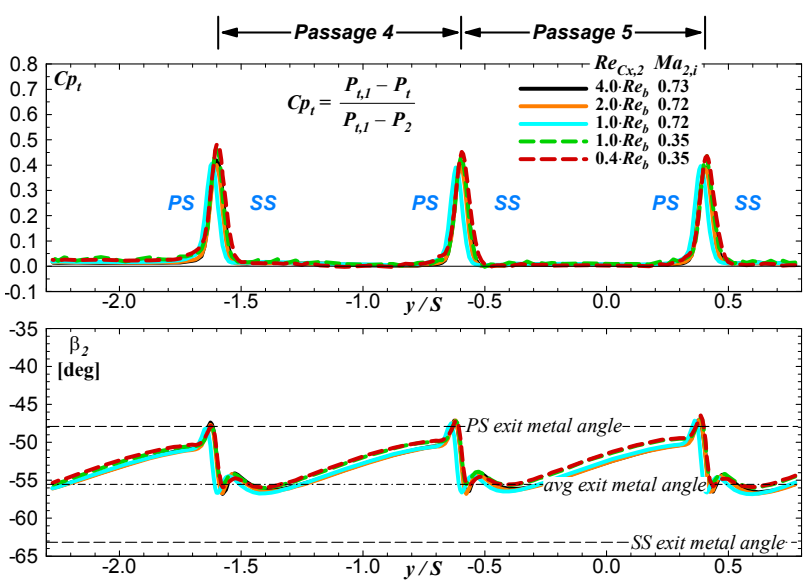

(b) High $T u$

Figure 17.-Effects of Reynolds number and exit Mach number at $i=-36.7^{\circ}$.

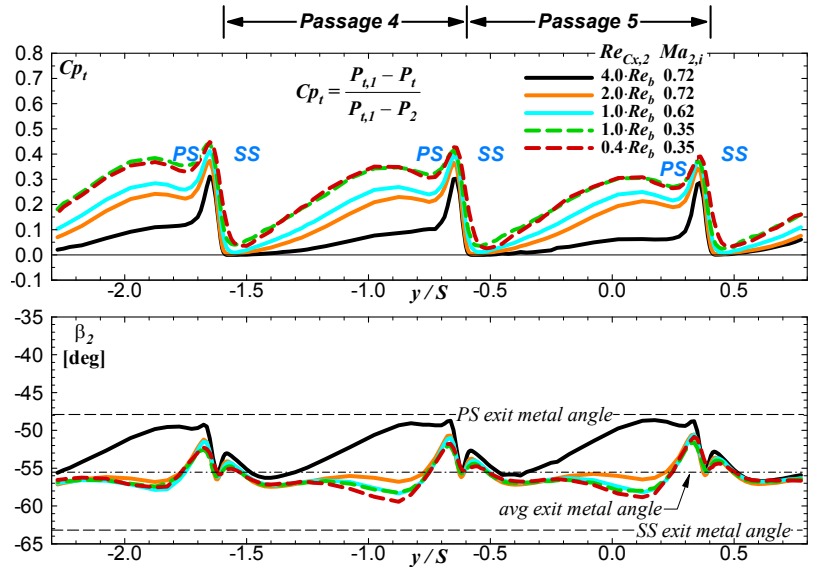

(a) Low $T u$

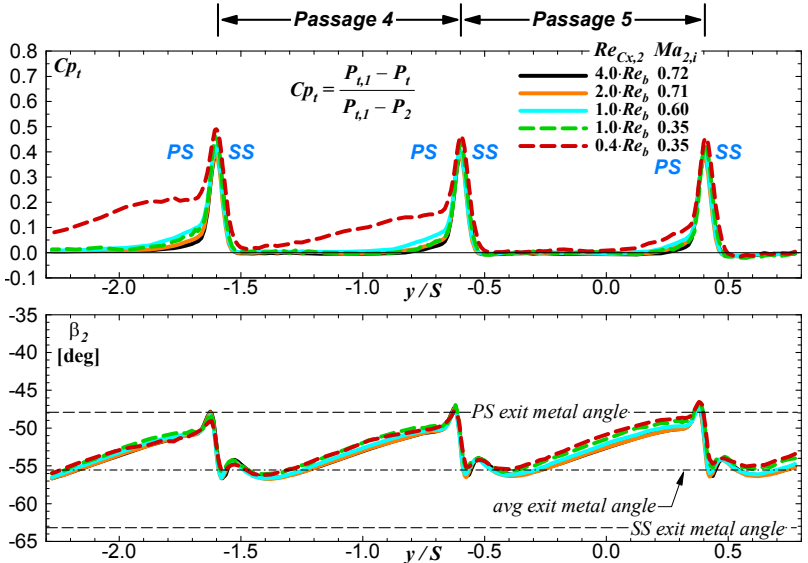

(b) High $T u$

Figure 18.-Effects of Reynolds number and exit Mach number at $i=-51.0^{\circ}$.

The effects of incidence angle variation at the highest and lowest Reynolds number conditions for the low (a) and high (b) $T u$ cases are summarized in Figures 19 and 20. The effects of an order of magnitude variation in Reynolds number are displayed across these figures. The three incidence angles represent the mission points; cruise $\left(i=+5.8^{\circ}\right)$, takeoff $\left(i=-36.7^{\circ}\right)$, and maximum mission incidence $\left(i=-46.0^{\circ}\right)$. For the highest Reynolds number $\left(4 \cdot R e_{b}\right)$ in Figure 19 for both low (a) and high (b) $T u$, the positive incidence produces the highest overall loss and decreases with decreasing incidence. High $T u$ produces much lower loss than low $T u$ and varies little at the negative incidence angles. The largest variance between $T u$ levels occur at the low Reynolds number $\left(0.4 \cdot R e_{b}\right)$ and Mach number $(0.35)$ condition, shown in Figure 20 . At low $\mathrm{Tu}$ (Fig. 20(a)) strong suction side separation is evident at the positive incidence angle. As the incidence decreases, the blade unloads (as observed in the blade loading diagrams) and the losses decrease. At the high negative incidence $\left(i=-46^{\circ}\right)$ the losses increase due to an extensive pressure-side separation. At high $T u$ (Fig. 20(b)) case the wake profile and loading indicate the flow remains attached and the losses decrease. The losses are similar to the high Reynolds number, where the loss is the highest at positive incidence and decreases with decreasing incidence. At the highest negative incidence angle there is evidence of a slight increase on the pressure side.

For all of the high $T u$ positive incidence cases, small regions of seemingly erroneous negative $C p_{t}$ values were observed on the PS sides of the wakes (Figs. 14(b), 19(b), and 20(b)). These values were not observed for the corresponding low $T u$ cases; are consistent and repeatable; and are outside the uncertainty range of the measurements. Full mapping of the inlet total pressure field was performed for the $i=+5.8^{\circ}$ case and no sufficiently high local $P_{t, 1}$ values were found. Potential other explanations, including flow unsteadiness 


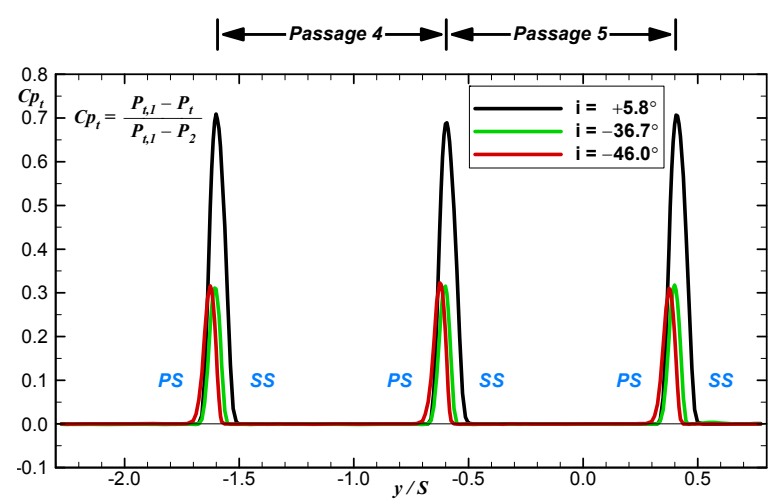

(a) Low $T u$

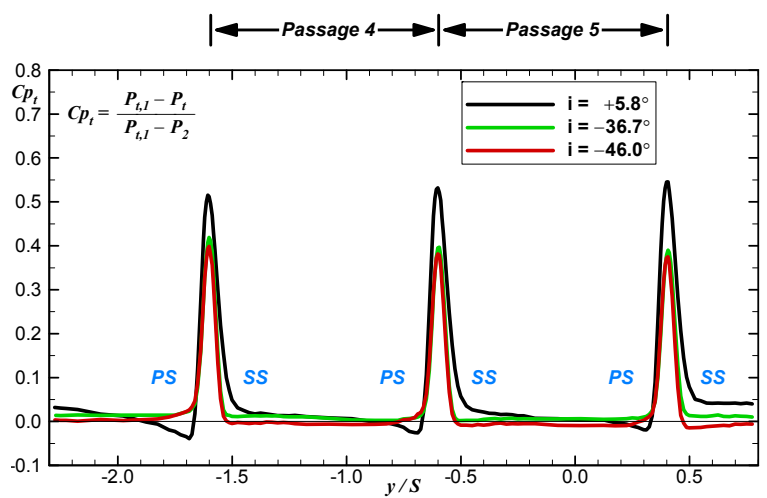

(b) High $T u$

Figure 19.-Effect of incidence angle at $R e_{C x, 2}=2.12 \times 10^{6}\left(4 \cdot R e_{b}\right)$ and $M_{2, i}=0.72$.

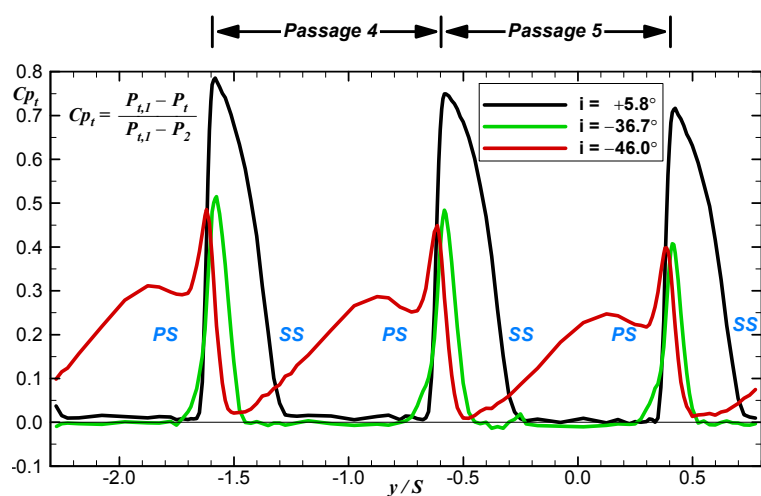

(a) Low $T u$

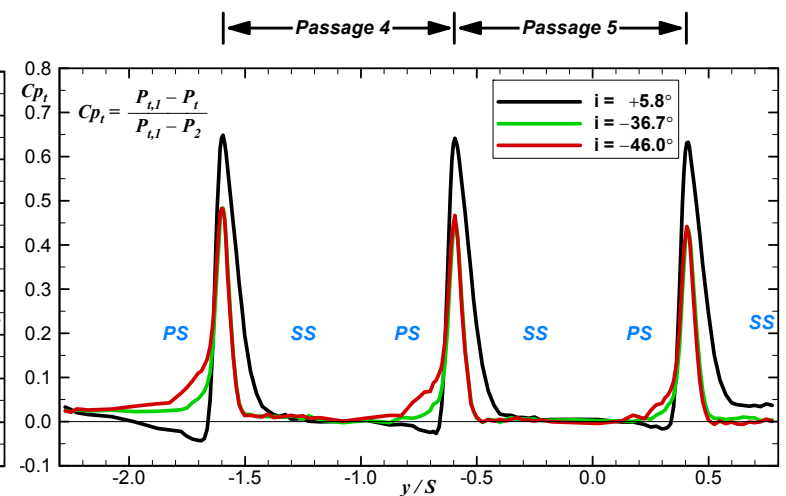

(b) High $T u$

Figure 20.-Effect of incidence angle at $\operatorname{Re}_{C x, 2}=2.12 \times 10^{5}\left(0.4 \cdot R e_{b}\right)$ and $M_{2, i}=0.347$.

(grid shedding); differing responses to high turbulence for Kiel versus five-hole probes; and the impact of streamwise velocity gradients on the local turbulent kinetic energy (production/destruction), were considered, but no viable justification could be found. Consideration of this repeatable, and yet apparently anomalous, total-pressure gradient continues.

\section{Loss Bucket and Flow Turning}

For both $T u$ cases, area-averaged integrations of the total-pressure data were used to calculate the midspan profile loss coefficients, $\omega$, for all 10 incidence angles and five flow conditions. The loss buckets (i.e., the midspan loss coefficients plotted as a function of incidence) for low and high $T u$ are provided in Figures 21(a) and (b). The integrations were calculated separately over two complete passages, 4 and 5. At low $T u$ and extreme negative incidence angles, passage-to-passage variations are quite evident in the scatter of the loss levels (Fig. 21(a)). These variations are attributable to the sensitivity of transitional flow with separation. Periodicity is improved at high $T u$, reducing scatter in the loss levels from passage to passage (Fig. 21(b)). The sensitivity of loss levels to Reynolds number at high $T u$ is greatly reduced and the losses collapse asymptotically to the high Reynolds number (turbulent) level. Loss levels remain nearly constant as the Mach number is varied from $M_{2, i}=0.72$ to $M_{2, i}=0.35$ at $1 \cdot R e_{b}$. It is interesting to note that the apparent pinch-point (invariance of loss with $R e$ ) at $i=-36.7^{\circ}$ of the low $T u$ data noted earlier (Ref. 4), was exhibited in high $T u$ data, arguably to an even greater degree. 


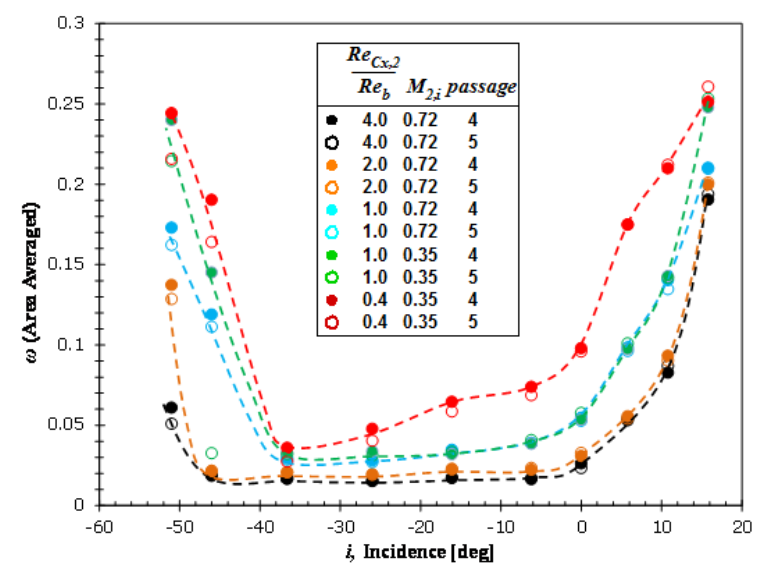

(a) Low Tu

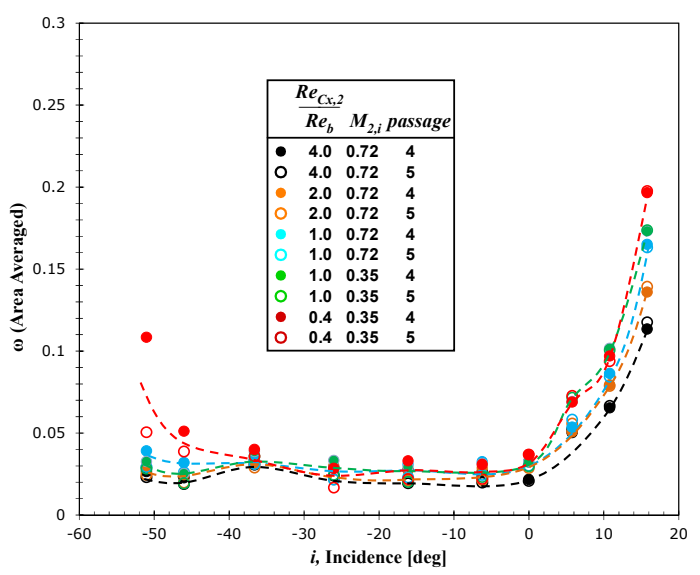

(b) High Tu

Figure 21.-Midspan loss versus incidence.

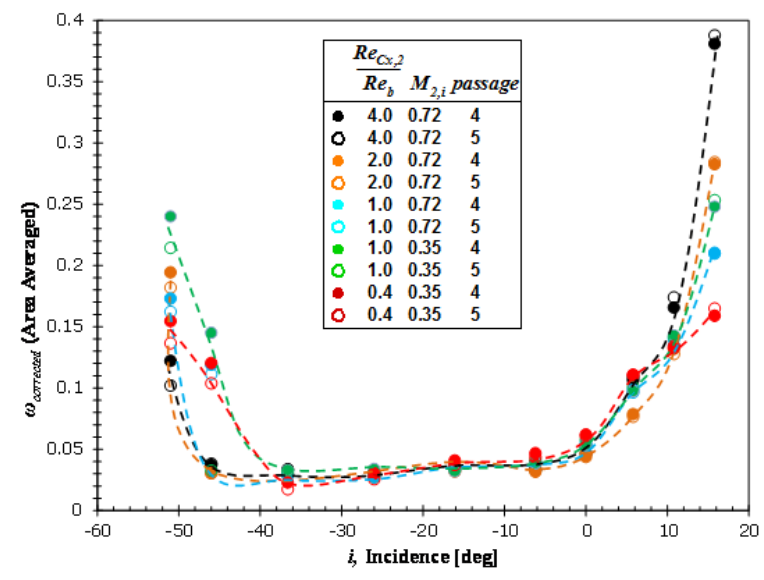

(a) Low $T u$

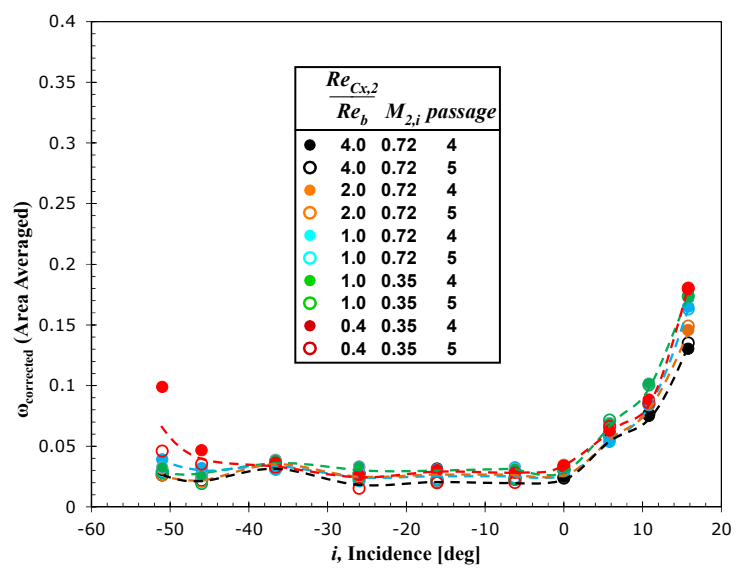

(b) High $T u$

Figure 22.- $R e^{-n}$ scaled midspan loss versus incidence.

The corrected midspan loss levels are plotted as a function of a corrected Reynolds number in Figures 22(a) and (b). The low $T u$ data strongly collapsed on the power-law $\omega \propto R e^{-0.5}$, (Fig. 22(a)), indicative of a significant influence of laminar flow on the midspan loss levels. For the high $T u$ data (Fig. 22(b)), a strong collapse was achieved with $\omega \propto R e^{-0.1}$, indicating that, as expected, the midspan losses were dominantly influenced by turbulent flow.

As carried out in McVetta et al. (Ref. 4), the high and low Tu midspan loss coefficients were re-plotted in terms of reduced loss and reduced incidence according to the Ainley-Mathieson (A-M) scaling $\left(\omega / \omega_{s}\right.$ versus $\left.i / i_{s}\right)$ (Ref. 15) as shown in Figure 23. The strong collapse found previously for low $T u$ data (Ref. 4) was repeated, as expected, for the high $T u$ data. It is noted that, if A-M scaling is applied about $i_{\text {opt }}=-26^{\circ}$, as shown in Figure 24, then not only do the data collapse strongly on the A-M scaling, but the A-M loss correlation (Ref. 15) was found to hold. With respect to this new reference zero incidence and associated loss level, the A-M correlation might be used to extrapolate negative incidence angles out to a range of angles that is far beyond the range of the present experiment.

The midspan deviation angle from the exit metal angle as a function of incidence and Reynolds number is shown in Figure 25(a) (low $T u$ ) and Figure 25(b) (high $T u$ ). At low $T u$, the deviation angle asymptotically approaches $\Delta \beta_{2}=2^{\circ}$ as the incidence decreases at the design exit Mach numbers and approaches $\Delta \beta_{2}=4^{\circ}$ at the lower Mach condition. As the angle approaches the extreme negative incidence angle, where the aerodynamic blockage on the pressure side causes a more negative discharge 
angle, the deviation angle shifts significantly. At high $T u$, the flow remains attached on the blade surface for the entire incidence range and the deviation angle asymptotically approaches $2^{\circ} \leq \Delta \beta_{2} \leq 3^{\circ}$ for all Reynolds numbers; differences (offset) between the baseline (0.72) and lower (0.35) exit Mach number conditions were again evident (Fig. 25(b)).

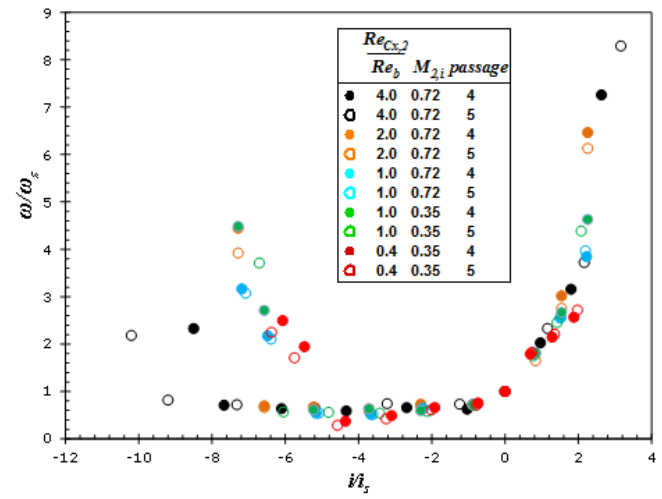

(a) Low $T u$

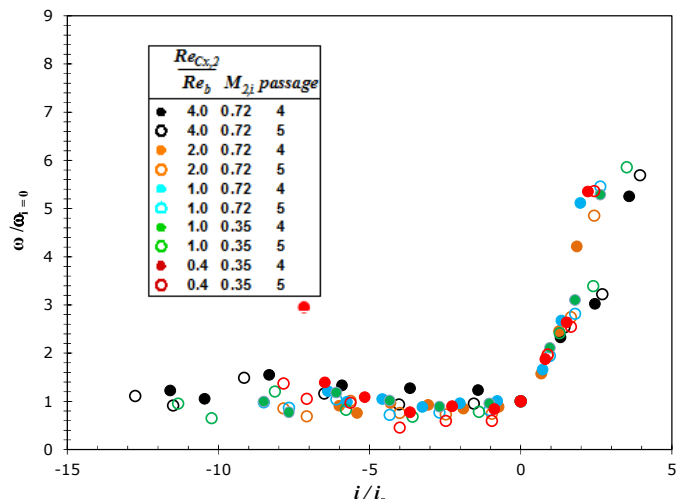

(b) High Tu

Figure 23.-Midspan loss bucket on ainley-mathieson scaling.

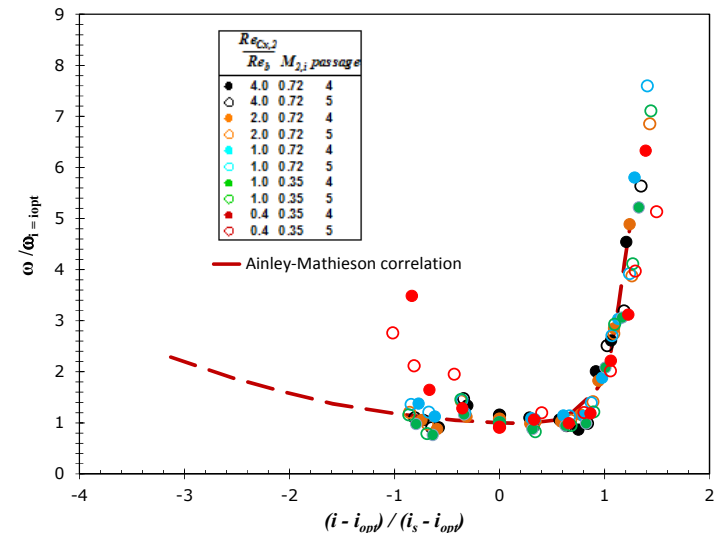

Figure 24.-Midspan loss bucket on ainley-mathieson scaling at high Tu.

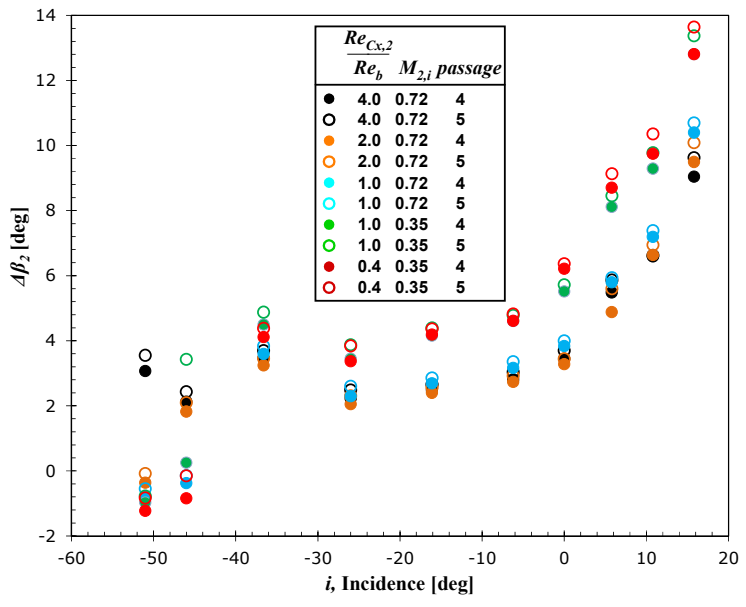

(a) Low $T u$

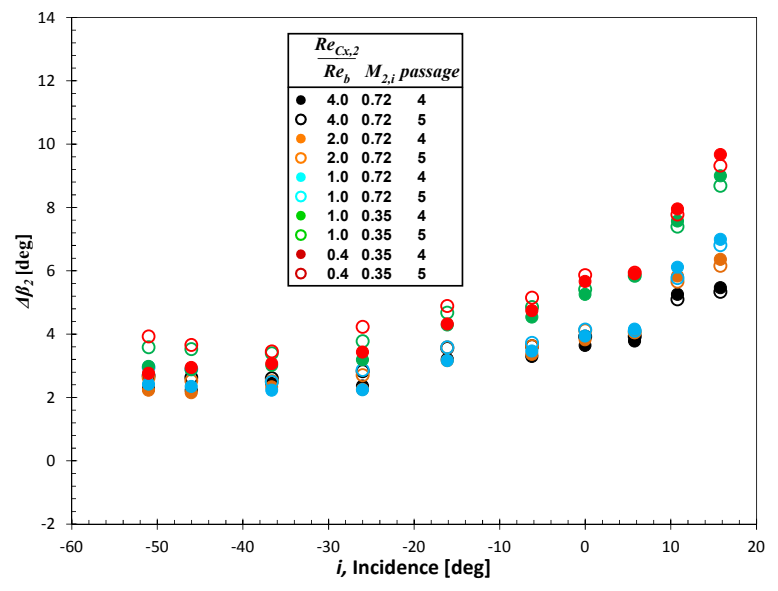

(b) High Tu

Figure 25.- Midspan deviation angle from exit metal angle as function of incidence and Reynolds number. 


\section{Conclusions}

A new set of aerodynamic performance data was obtained for VSPT blading at engine relevant (high $T u$ ) inlet turbulence conditions. The dataset complements an earlier dataset acquired at low inlet turbulence levels as required to achieve mission-relevant transitional flow behavior within the Reynolds number capability of the experimental facility. The high $T u$ data were acquired over the same wide range of incidence angles and repeated the Mach/Reynolds number conditions of the earlier low $T u$ test matrix.

As in the earlier low $T u$ work, exit total-pressure and exit flow angles were examined to understand the strength and impact of secondary flow fields at the highly loaded design incidence $\left(i=+5.8^{\circ}\right)$ condition of LCTR cruise and at the low-load, high negative incidence $\left(i=-36.7^{\circ}\right)$ of LCTR takeoff. The turbulence grid of the high $T u$ entry effectively reduced by half the thickness of the turbulent endwall boundary layers at cascade inlet, leading to significantly less aerodynamic blockage in the test section.

Comparison of blade loading diagrams at the low $T u$ and high $T u$ conditions showed that the flow at the high $T u$ conditions remains attached on both SS and PS at all incidence, Reynolds number, and Mach number conditions. This is in strong contrast to the blade loading at low $T u$ which exhibited separation, transition, reattachment on both suction and pressure sides of the blade, depending on incidence angle. The pressure side cove separation, a key feature in the data at low $T u$, was not evident in the high $T u$ data. Given that the lower mission-relevant Reynolds numbers were not achievable in the NASA turbine cascade test facility, it remains for separate work (Refs. 16 and 17) to assess transitional flow characteristics at combined high $T u$ and cruise-relevant Reynolds numbers.

Midspan loss levels at the highly loaded design incidence at high $T u$ were found to be slightly lower than at low $T u$ where the flow separated and reattached. The midspan loss at high $T u$ was found to be higher than at low $T u$ at lower load conditions at which the low $T u$ flow did not separate on the pressure or suction sides. Spanwise profiles of loss indicated minimum turning was achieved at the spanwise location at which the pressure-side leg of the horseshoe vortex exited the blade row. This position change in the two entries (low and high $T u$ ) was attributable to the magnitude of the incoming turbulent endwall boundary-layer with and without the grid in place and the subsequent impact on the amount of low-momentum flow (aerodynamic blockage) at the hub/suction-side corner.

Midspan profile loss buckets at high $T u$ collapsed strongly on a turbulent power-law scaling $\left(\omega \propto R e^{-0.1}\right)$ reflective of turbulent flow conditions. As in previous low $T u$ work, Ainley Mathieson scaling illustrated strong data collapse. Unlike at low $T u$, the collapse was found to be independent of Reynolds number and, given proper selection of reference incidence, in strong agreement with the Ainley-Mathieson profile loss versus incidence correlation.

\section{References}

1. Welch, G.E., "Assessment of Aerodynamic Challenges of a Variable-Speed Power Turbine for Large Civil Tilt-Rotor Application," Proc. AHS Int. $66^{\text {th }}$ Annual Forum, May, 2010; also NASA/TM-2010-216758, Aug. 2010.

2. Johnson, W., Yamauchi, G.K., and Watts, M.E., "NASA Heavy Lift Rotorcraft Systems Investigation," NASA TP-2005-213467, Sep., 2005.

3. Acree, C.W., Hyeonsoo, Y., and Sinsay, J.D., "Performance Optimization of the NASA Large Civil Tiltrotor," Proc. Int. Powered Lift Conf., London, UK, July 22-24, 2008.

4. McVetta, A.B., Giel, P.W., Welch, G.E., "Aerodynamic Measurements of A Variable-Speed PowerTurbine Blade Section in a Transonic Turbine Cascade At Low Inlet Turbulence," GT2013-94695, ASME Turbo Expo., San Antonio, Texas, USA, June 2013; also NASA/TM-2013-218069.

5. Ameri, A., Giel, P.W., McVetta, A.B., "Validation of a CFD Methodology for Variable Speed Power Turbine Relevant Conditions," GT2013-95030, ASME Turbo Expo., San Antonio, Texas, USA, June 2013. 
6. Ameri, A., Giel, W., Flegel, A.B., 2014, "Simulation of VSPT Experimental Cascade under High and Low Free-Stream Turbulence Conditions," to be presented at the 50th AIAA/ASME/SAE/ASEE Joint Propulsion Conference, Cleveland, Ohio, July 2014.

7. McVetta, A.B., Giel, P.W., and Welch, G.E., "Aerodynamic Investigation of Incidence Angle Effects in a Large Scale Transonic Turbine Cascade," AIAA-2012-3879, Proc. 48th AIAA/ASME/SAE/ASEE Joint Propulsion Conference \& Exhibit, Atlanta, GA, Jul-Aug. 2012.

8. Giel, P.W., Thurman, D.R., Lopez, I., Boyle, R.J., Van Fossen, G.J., Jett T.A., Camperchioli, W.P., La, H., "Three Dimensional Flow Field Measurements in a Transonic Turbine Cascade," ASME 96GT-113, 1996; also NASA/TM-107388 and U.S. Army ARL-TR-1252.

9. Giel, P.W., Bunker, R.S., VanFossen, G.J., and Boyle, R.J., "Heat Transfer Measurements and Predictions on a Power Generation Gas Turbine Blade," ASME 2000-GT-0209; Also NASA/TM2000-210021.

10. Giel, P.W., Boyle, R.J., and Bunker, R.S., "Measurements and Predictions of Heat Transfer on Rotor Blades in a Transonic Turbine Cascade," J. Turbomachinery, 126 (1), pp. 110-121, Jan. 2004.

11. Boyle, R.J., Lucci, B.L., Verhoff, V.G., Campercholi, W.P., and La, H., "Aerodynamics of a Transitioning Turbine Stator Over a Range of Reynolds Numbers," ASME 98-GT-285, 1998.

12. Thurman, A., Giel, P.W., Flegel, A.B., "Inlet Turbulence and Length Scale Measurements in a Large Scale Transonic Turbine Cascade," to be presented at the 50th AIAA/ASME/SAE/ASEE Joint Propulsion Conference, Cleveland, Ohio, July 2014.

13. Ford, A., Bloxham, M., Turner, E., Clemens, E., and Gegg, S., "Design Optimization of IncidenceTolerant Blading Relevant to Large Civil Tilt-Rotor Power Turbine Applications," NASA/CR2012-217016, Dec. 2012.

14. Hoheisel H., Kiock, R., Lichtfuss, H.J., and Fottner, L., 1987, "Influence of Free-Stream Turbulence and Blade Pressure Gradient on Boundary Layer and Loss Behavior of Turbine Cascades," J. Turbomachinery, 109, April, pp. 210-219.

15. Ainley, D.G. and Mathieson, G.C.R., "A Method of Performance Estimation for Axial-Flow Turbines," Aeronautical Research Council (ARC), R\&M 2974, 1957.

16. Moualeu, L.P., Long, J.E., Ames, F.E., "Midline Heat Transfer and Pressure Measurements on an Incident Tolerant Blade Section for a Variable Speed Power Turbine at Low to Moderate Reynolds Numbers in a Transonic Turbine Cascade," to be presented at the 50th AIAA/ASME/SAE/ASEE Joint Propulsion Conference, Cleveland, Ohio, July 2014.

17. Stahl, K., Moualeu, L.P., Long, J.E., Ames, F.E., "Heat Transfer Measurements in a Compressible Flow Vane Cascade Showing the Influence of Reynolds Number, Mach Number, and Turbulence Level on Transition and Augmentation of Laminar Heat Transfer by Free-Stream Turbulence," to be presented at the 50th AIAA/ASME/SAE/ASEE Joint Propulsion Conference, Cleveland, Ohio, July 2014. 


